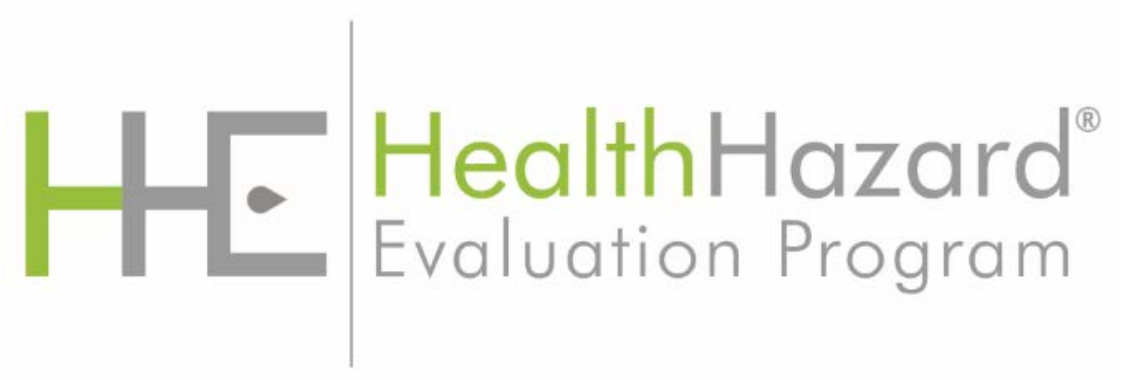

\title{
Evaluation of Exposures to Metals and a Perceived Excess of Cancer Cases in a Tra in Maintenance Facility
}

HHE Report No. 2019-0106-3378

March 2021 
Authors: Michael P. Grant, ScD

\section{Laura Reynolds, MPH, BSN, RN}

\section{Hannah Echt, MS}

Desktop Publisher: Shawna Watts

Editor: Cheryl Hamilton

Industrial Hygiene Field Assistance: Catherine Beaucham, Eric Glassford, Donald Booher

Logistics: Donald Booher and Kevin Moore

Medical Field Assistance: Shawn Armes, Reed Grimes, David Lang, Debbie Sammons

Keywords: North American Industry Classification System (NAICS) 488210 (Support Activities for Rail Transportation); New York, Dust, Metals, Lead, Railroad, Train, Maintenance, Cancer

\section{Disclaimer}

The Health Hazard Evaluation Program investigates possible health hazards in the workplace under the authority of the Occupational Safety and Health Act of 1970 [29 USC 669a(6)]. The Health Hazard Evaluation Program also provides, upon request, technical assistance to federal, state, and local agencies to investigate occupational health hazards and to prevent occupational disease or injury. Regulations guiding the Program can be found in Title 42, Code of Federal Regulations, Part 85; Requests for Health Hazard Evaluations [42 CFR Part 85].

\section{Availability of Report}

Copies of this report have been sent to the employer, employees, and union at the facility. The state and local health departments and the Occupational Safety and Health Administration Regional Office have also received a copy. This report is not copyrighted and may be freely reproduced.

\section{Recommended Citation}

NIOSH [2021]. Evaluation of exposures to metals and a perceived excess of cancer cases in a train maintenance facility. By Grant MP, Reynolds L, Echt H. Cincinnati, OH: U.S. Department of Health and Human Services, Centers for Disease Control and Prevention, National Institute for Occupational Safety and Health, Health Hazard Evaluation Report 2019-0106-3378, https://www.cdc.gov/niosh/hhe/reports/pdfs/2019-0106-3378.pdf. 


\section{Main Report}

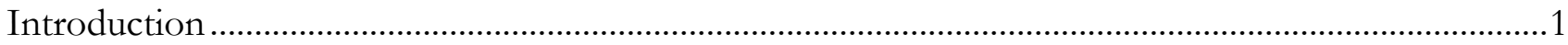

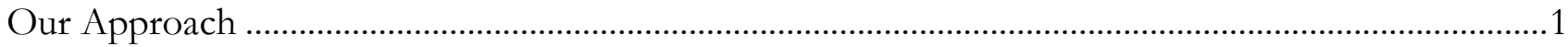

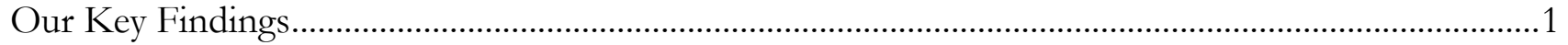

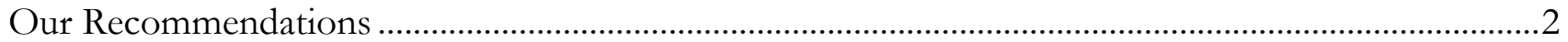

\section{Supporting Technical Information}

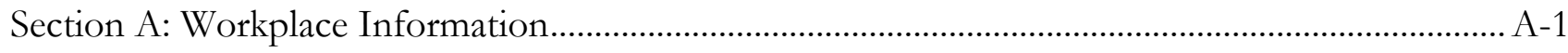

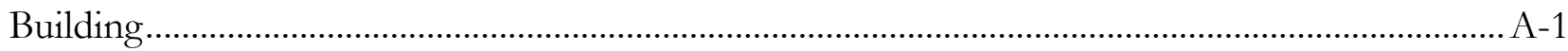

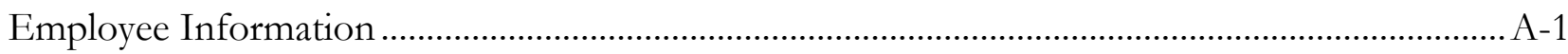

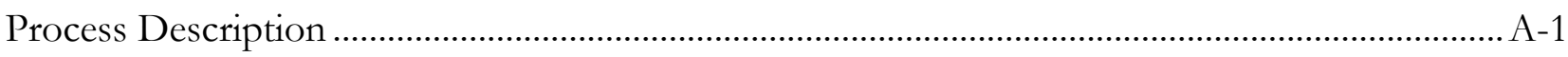

Section B: Methods, Results, and Discussion ……………………………………………….... B-1

Methods: Observations of Work Processes, Practices, and Conditions .......................................... B-1

Results: Observations of Work Processes, Practices, and Conditions ............................................ B-1

Methods: Exposure Assessment ........................................................................................... B-3

Results: Exposure Assessment .......................................................................................... B-4

Methods: Medical Survey and Reported PPE Use ………………………………………….... B-4

Results: Medical Survey and Reported PPE Use …………………………………………….. B-5

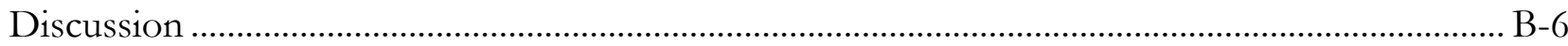

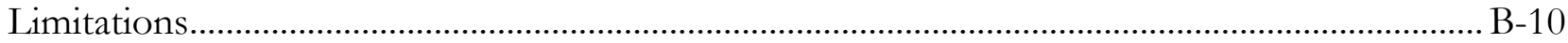

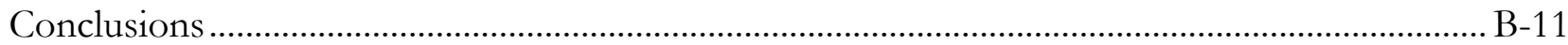

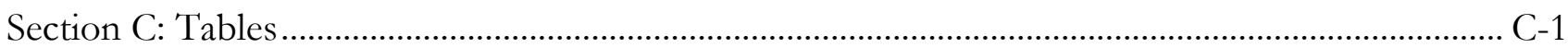

Section D: Occupational Exposure Limits .............................................................................. D-1

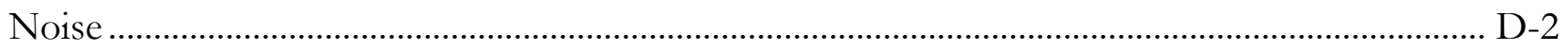

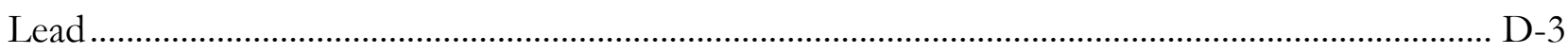

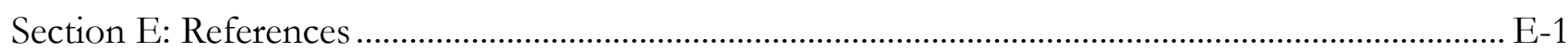


This page left intentionally blank 


\section{Introduction}

\section{Request}

A union at a train maintenance facility requested a health hazard evaluation concerning employee exposure to metals and a perceived excess of cancer.

\section{Workplace}

The work took place in a variety of workshops (shops) located at the facility. We focused the evaluation on six shops that worked on different maintenance and repair tasks: truck, wheel, motor, electronics, contactor, and tin. The facility was open 24 hours and staffed three shifts, although not all shops had three shifts. This evaluation focused on first shift employees. All employees worked a single 8-hour shift with an opportunity for overtime depending on workload and staffing levels. There were multiple unions on site, and all employees belonged to a union. Each shop performed different work supporting the repair and maintenance of trains.

To learn more about the workplace, go to Section A in the Supporting Technical Information

\section{Our Approach}

We visited the facility twice, in June and July 2019. During our visits, we did the following activities:

- Observed work processes, work practices, and conditions.

- Held opening and closing meetings with management and union representatives.

- Spoke informally to employees in each support shop about health and safety concerns.

- Measured employee exposures to metals in air.

- Administered medical surveys.

- Measured blood lead levels of employees in the electronics shop.

To learn more about our methods, go to Section B in the Supporting Technical Information

\section{Our Key Findings}

\section{Employees had concerns about their workplace exposures and the potential health effects}

- Employees reported concerns about exposure to metals and dust while working. We observed that workstations were generally clean, but there was visible dust on the top of duct work and equipment (e.g., tool cabinets) that were difficult to reach for routine cleaning.

- Some employees reported that they were concerned about cancer. 


\section{Training and hazard communication could be improved}

- We observed inconsistent use of personal protective equipment throughout the facility and varying levels of understanding of the risks posed by the types of work being performed.

- Previous sampling data revealed no history of overexposures, but employees reported concerns about potential exposures.

- Employees expressed concern about potential exposures to varnish chemicals and cadmium. However, the vacuum pressure impregnation (VPI) process for applying varnish on the coils of electric motors was no longer used, and the cadmium-containing contactors had been enclosed for years.

\section{We found no overexposures to metals}

- Air sampling showed no exposures to metals that were above relevant occupational exposure limits.

- Electronic shop employees' blood lead levels were within the normal range.

Four employees reported having cancer, each diagnosed with a different type

- These results were not consistent with the cancers being potentially caused by a work-related exposure.

- A large-scale epidemiologic study would be required to determine whether there is an excess of cancer in this population. Management and union representatives were referred to the state health department to follow up on cancer concerns.

To learn more about our results, go to Section B in the Supporting Technical Information

\section{Our Recommendations}

The Occupational Safety and Health Act requires employers to provide a safe workplace.

Benefits of Improving Workplace Health and Safety:
个 Improved employee health and well-being
$\uparrow$ Enhanced image and reputation
个 Better workplace morale
个 Superior products, processes, and services
个 Easier employee recruiting and retention
$\uparrow$ May increase overall cost savings

The recommendations below are based on the findings of our evaluation. For each recommendation, we list a series of actions you can take to address the issue at your workplace. The actions at the beginning of each list are preferable to the ones listed later. The list order is based on a well-accepted approach called the "hierarchy of controls." The hierarchy of controls groups actions by their likely 
effectiveness in reducing or removing hazards. In most cases, the preferred approach is to eliminate hazardous materials or processes and install engineering controls to reduce exposure or shield employees. Until such controls are in place, or if they are not effective or practical, administrative measures and personal protective equipment might be needed. Read more about the hierarchy of controls at https://www.cdc.gov/niosh/topics/hierarchy/.

We encourage the company to use a health and safety committee to discuss our recommendations and develop an action plan. Both employee representatives and management representatives should be included on the committee. Helpful guidance can be found in "Recommended Practices for Safety and Health Programs" at https://www.osha.gov/shpguidelines/index.html.

\section{Recommendation 1: Improve hazard communication and training}

Why? Hazard communication and training are key components of any health and safety program. It is important to clearly explain what hazards exist in the workplace and address concerns raised by employees about potential hazards that they may encounter while working. It is also important to provide training about what controls are needed (i.e., engineering controls, administrative practices, or personal protective equipment) for the variety of tasks employees complete during the workday.

We found that hazard communication between management and employees could be improved around concerns about chemical exposures from the VPI process, visible dust in the facility, and cadmium in the contactor shop. We learned that the VPI process had been outsourced and that equipment no longer contained chemicals. We also learned that the contactor shop was no longer in direct contact with cadmium. Historical data showed that there were no overexposures to metals. Our air sampling also showed no overexposures to metals.

We observed inconsistent personal protective equipment usage within the support shops and confusion among employees about personal protective equipment requirements while doing certain tasks. Both union and management representatives expressed concern about the perceived excess of cancer cases among employees and wanted to continue to evaluate whether employees were diagnosed with more cancer than the general population.

How? At your workplace, we recommend these specific actions:

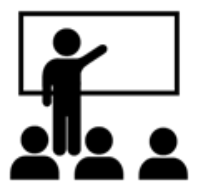

\section{Provide periodic training and communication about relevant occupational safety and health topics.}

- Communicate to employees that visible dust on top of ventilation ducts does not present a hazard if it is not touched or disturbed. Proper use of engineering controls and personal protective equipment along with appropriate cleaning of workstations should adequately control exposures to dust produced in each shop. 
- Explain to employees that the VPI process had been outsourced and the equipment was decommissioned. There is no risk of exposure because there are no longer any chemicals in the equipment.

- Train employees about the potential hazards in their work and the proper ways to protect themselves. Training will increase awareness and should be used to address concerns held by employees.

\section{Provide training about the personal protective equipment requirements} in each shop.

- Train employees upon hiring and at least annually or as needed with each shop to increase knowledge, compliance, and proper wearing of protective equipment.

- Reinforce the importance of the respiratory protection program requirements for medical clearance, training, and fit testing.

\section{Review procedures for safety data sheet access from computer kiosks during the annual hazard communication training.}

- Provide information about kiosk locations, log-in, and searching for safety data sheets. Also provide a mechanism for reporting issues related to kiosk access.

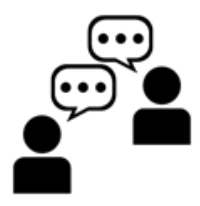

\section{Communicate with employees about the perceived excess of cancer cases} and other health concerns and the steps being taken to address those concerns.

- Provide regular updates to the unions and safety committee related to the steps being taken and what information has been learned at each step.

- Refer employees to the facility's occupational health program or their primary care provider to discuss their individual health concerns and questions about cancer.

\section{Recommendation 2: Improve hygiene and cleaning practices}

Why? Proper hygiene and regular cleaning of the workplace can prevent unnecessary exposures to metals and dust.

We were told that employees were given time for daily workspace cleaning and that they could set aside time for more extensive cleaning each week. We did not observe employees doing extensive cleaning during our visits, but employees had concerns about dust accumulation and potential exposures to metals. 


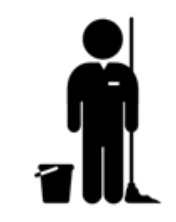

Reinforce the importance of daily and weekly cleaning of commonly used areas of all workstations and break areas.

- Clean workstations and break areas daily, focusing on commonly used areas.

- Encourage employees to perform more extensive cleaning each week to prevent long-term buildup of dust.

- Provide training to employees about the proper methods to use while cleaning. Include information about following the manufacturer's instructions for using cleaning products.

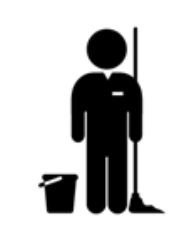

Use wet methods or high efficiency particulate air (HEPA) filter vacuums to clean metal dust.

- Provide training to employees about the proper methods to use while cleaning. Wet methods (e.g., mops or surface wipes) and HEPA filtered vacuums are preferred when cleaning up metal dust from workstations.

- Instruct employees that compressed air is never an acceptable method for cleaning up metal dust. Dry sweeping should also be discouraged.

\section{Provide metal-removing soap in shops where employees are exposed to heavy metals.}

- Provide training to employees about the proper methods for using metal-removing soap (e.g., always use the metal-removing soap prior to using an abrasive hand cleaner). Make sure employees are aware that abrasive cleaners can remove the outer layer of skin and could increase metal absorption through the skin.

- Instruct employees to wash hands with metal-removing soap each time they leave their workstation to eat, drink, smoke, or use the bathroom.

\section{Consume all food and beverages away from production areas.}

- Move appliances (e.g., toasters, microwaves, and coffee makers) to areas separated from the production areas by floor to ceiling walls and a door that closes.

- Provide training to employees about the importance of not consuming food or beverages at workstations and of washing their hands before smoking, eating, or drinking. Include information about how handwashing is also important prior to using any appliances in break areas. 


\section{Recommendation 3: Address other health and safety issues we identified during our evaluation}

Why? A workplace can have multiple health hazards that cause employee illness or injury. Similar to the ones identified above, these hazards can potentially cause serious health symptoms, lower morale and quality of life for your employees, and possibly increase costs to your business. We saw the following potential issues at your workplace:

- Parts were being sprayed in the paint booth with a configuration that could unnecessarily expose employees to paint meant to be captured by the booth.

- The National Institute for Occupational Safety and Health (NIOSH) criteria were not used in previous noise evaluations.

- Some shops had powder-free latex gloves available for use; latex is a potential allergen.

- Employees told us that they suspected that a sand blasting cabinet adjacent to the wheel shop had a leak.

Although they were not the focus of our evaluation, these hazards could cause harm to your employees' health and safety and should be addressed.

How? At your workplace, we recommend these specific actions:

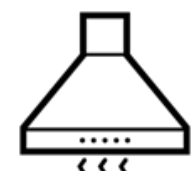

II\}

\section{Spray paint with the parts in the appropriate orientation to maintain} correct airflow.

- Keep the part between the employee and the air filters so that the air pulls paint away from the employee and into the filter.

- Paint the rear of the part by rotating the part to maintain the correct positioning.

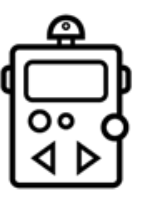

\section{Always follow NIOSH criteria when monitoring for noise to be more protective.}

- Use a noise dosimeter that can simultaneously sample using the Occupational Safety and Health Administration (OSHA), NIOSH, and the American Conference of Governmental Industrial Hygienists $\left(\mathrm{ACGIH}^{\circledR}\right)$ parameters.

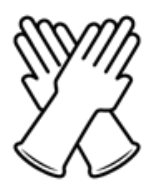

\section{Remove latex gloves from the facility and work with the general foremen to prevent future purchases.}

- Remove latex gloves from the master list of items that are allowed to be ordered.

- Train general foremen about why latex gloves should not be ordered, and which gloves are suitable replacements. Latex gloves are a potential allergy source and should be removed from the facility. 
Investigate the sand blasting cabinet to identify and repair any leaks in the system.

- Provide refresher training for employees on how they are to report maintenance issues. Incorporate this information into training for new hires. 


\section{Supporting Technical Information}

Evaluation of Exposures to Metals and a Perceived Excess of Cancer Cases in a Tra in Ma intenance Facility HHE Report No. 2019-0106-3378

March 2021 


\section{Section A: Workplace Information}

\section{Building}

The facility was located on approximately 23 acres of land. There were multiple train tracks leading into buildings (referred to as the car shop) where maintenance and repairs were made. Adjacent to the car shop were a variety of support shops. Each shop specialized in the repair of certain parts of the train. The facility was open 24 hours and staffed three shifts, although not all shops had three shifts.

\section{Employee Information}

We made an initial site visit to observe work and speak with employees from every shop at this facility. After reviewing our observations and notes from conversations, we narrowed the scope of the evaluation to the following six shops: truck, wheel, motor, electronics, contactor, and tin. The work within each shop did not change by shift, therefore, this evaluation focused on first shift employees. All employees worked a single 8-hour shift with an opportunity for overtime depending on workload and staffing levels. Job titles included car repairman, electrician, gang foreman, machinist, and laborer/oiler. There were multiple unions on site and all employees belonged to one of the unions.

\section{Process Description}

There were multiple shops within this facility that supported the overall efforts to perform maintenance and repairs on trains. When train components needed to be repaired or maintained, they were removed from the train and sent to the appropriate shop. We included six of those shops in our evaluation. We also observed a whole train being moved in the car shop. Laborers/oilers provided general support for all the shops in the facility including light cleaning and maintenance.

\section{Truck Shop}

The railroad truck is the frame of the railcar that holds the wheelsets (an axle with two wheels). Employees in the truck shop were tasked with repairing various truck components and mounting the wheelsets to the truck chassis. Employees operating in this shop included laborers/oilers, electricians, car repairmen, and machinists.

Machinists operated a wheel lathe in the basement directly below the truck shop. The wheel lathe cut the wheel profile to desired specifications and shaved the wheels in order to remove flat spots. Car repairmen operated an overhead crane to lift wheelsets and trucks to areas where they could be attached to one another. They also operated a vehicle lift embedded into the floor to lift the truck chassis so they could work under it. Car repairmen used pneumatic wrenches to attach wheelsets to trucks and angle grinders to polish bearings on the truck's axle box. Electricians in the truck shop knelt on a pad inside of the trucks to oil parts, insulate the motor box, and secure parts on the truck with impact wrenches. Once the electrical components of the truck were installed, electricians rolled the truck into a semienclosed area and power-washed the trucks with a degreaser. 


\section{Wheel Shop}

The wheel shop was responsible for the maintenance and repair of the wheels of the trains. Axles with wheels attached were rolled into this shop, disassembled, cleaned, repaired if needed, and reassembled on the axles. Finished axles were moved to another location where the truck shop would install them onto trucks. Machinists in this shop used lathes to true the wheels and axles and overhead cranes to move parts around the shop.

\section{Motor Shop}

The motor shop had electricians, machinists, and car repairmen who were responsible for all aspects of motor maintenance and repair. Motors that had been removed from trains were brought to this shop, disassembled, cleaned, repaired if needed, and reassembled. Some components required sandblasting or painting. There were dedicated sand blasting booths and a booth dedicated for painting in this shop. We learned that the VPI process for applying varnish on the coils of electric motors was no longer used. Employees in this shop expressed concerns to us about potential past exposures to the chemicals used in the VPI process. Employees were also concerned about potential exposures to chemicals from the decommissioned VPI equipment that is still in the facility.

\section{Electronics Shop}

The electronics shop included electricians who repaired and assembled the electrical components of the rail car. Electricians in this shop used soldering irons with leaded soldering wire and manual and electronic screwdrivers to attach parts to circuit boards. They then tested the circuit boards to determine if they were fit for use. Electricians also tested electrical cables' voltage/current and cleaned electrical parts with a degreaser and citrus-based cleaner. Electricians also sandblasted aluminum or other metal sheets as needed. Sandblasting took place in a separate, enclosed room and respirator use was required in this area.

\section{Contactor Shop}

The contactor shop had electricians who were responsible for repairing and replacing contactors. Contactors are relays used to switch power from the source to the electric motor. Employees informally told us that they used to have to open the cadmium-containing contactors in order to clean and repair them. We learned that the contactors are now completely contained and are simply removed and replaced when necessary. The new process with enclosed contactors should eliminate much of the potential exposures to metals.

\section{Tin Shop}

The tin shop is primarily responsible for fabricating tin components. Tinsmiths operated arbor presses to punch holes into sheet metal, flour drill presses to drill holes into tin blocks, sheet metal cutters to cut tin sheets to length, and an engraving machine to create tin placards. Welders in the tin shop welded tin components together and used angle grinders to polish these components. Employees in this shop expressed concerns to us about potential past exposures to the chemicals used in the VPI process. Employees were also concerned about potential exposures to chemicals from the decommissioned VPI equipment that is still in the facility. We were shown some chemical storage tanks adjacent to the shop that used to contain chemicals used in the VPI process. 


\section{Moving Trains in the Car Shop}

Trains were moved in and out of the car shop for a variety of reasons. We observed an employee, known as "the Bug Guy," apply power to three trains and move them in the car shop. The process for energizing the trains consisted of applying a "stinger" that directed voltage into the train's electrical system so that it could move itself. 


\section{Section B: Methods, Results, and Discussion}

\section{Methods: Observations of Work Processes, Practices, and Conditions}

We evaluated the following during our site visits:

- Work processes

- Personal protective equipment (PPE) use

- Workplace conditions

\section{Results: Observations of Work Processes, Practices, and Conditions}

\section{Overall}

- Employees reported concerns about visible contamination on workstation surfaces, visible dust on top of duct work, and general cleanliness conditions in the facility.

- Employees were given time for daily cleaning, and employees told us that they were supposed to set aside time weekly for deeper cleaning. We did not observe employees engaging in extensive cleaning during our visits.

- All shops had a variety of PPE available for employees. We were told that the foreman of each shop was responsible for purchasing and maintaining PPE supplies for their shop.

- We observed a variety of PPE ensembles being used in each shop with little consistency. For example, we observed four employees working on each side of a truck and all four employees were wearing different types and combinations of PPE. We asked multiple employees in all six shops on multiple days about the PPE they were wearing and why they were wearing it. When asked, employees in all shops were unaware of the appropriate PPE ensemble required for the tasks they were performing.

- Some employees reported that they did not know how to access safety data sheets. We learned that there are computer kiosks located around the facility and that employees should be able to log into any of them. When we asked to observe this process, management had difficulty logging into one of the kiosks.

\section{Truck Shop}

The machinist operating the wheel lathe wore earplugs, work clothes, safety glasses, and boots. They made sure that all individuals in the area had hearing protection. We observed some car repairmen wearing aprons, hard hats, steel-toed boots, and latex gloves. We observed one car repairman not wearing a hardhat bump his head while working under the truck chassis. While grinding, one car repairmen wore latex gloves and earmuffs, and donned an R95 respirator over his beard. While working on the trucks, electricians wore Tyvek ${ }^{\circledR}$ suits on the lower halves of their bodies and powder-free latex gloves. One electrician had on earplugs, although the electrician operating the impact wrench did not have on any hearing protection. While power washing the trucks, the electrician wore latex gloves and a full Tyvek suit. 


\section{Wheel Shop}

We observed employees wearing ear plugs, safety glasses, and steel-toed boots. There was a small sandblasting cabinet adjacent to the main shop. Employees told us that the sand blasting cabinet had a leak and that they were concerned about exposures when the cabinet was in use. We did not observe any sandblasting during our visit.

\section{Motor Shop}

We observed employees generally wearing latex gloves and safety glasses when disassembling, cleaning, machining, and reassembling motor assemblies. We observed most employees using hearing protection when operating loud equipment (e.g., impact drill). Employees wore R95 respirators when sandblasting. Some employees performing sandblasting had facial hair that would have interfered with the seal on the respirators. Employees wore an R95 or N95 respirator, face shield, earmuffs, and safety glasses when cutting. Employees were observed using compressed air to blow dust and metal shavings off machines. The paint booth was used to apply paint to various components of the motor assembly. We observed one employee wearing an elastomeric half mask respirator with combination P100/OV cartridges while painting in the paint booth. We learned that that the filters in the paint booth were replaced every six months based on recommendations from the vendor. There was a log on the booth to record when the filters were replaced. We were told that the gang foreman schedules the replacements. Employees informed us that they were concerned about exposures to paint vapors. We observed employees using the paint booth with a configuration that could unnecessarily expose employees to paint meant to be captured by the booth. Instead of spraying the parts with the direction of airflow, the employees were seen moving around the parts and spraying paint against the direction of airflow, potentially exposing themselves to the paint and vapors.

Although it is no longer used, employees in this shop told us that they were concerned about the VPI equipment remaining in the facility. We learned that this equipment has been decommissioned and has not been used for a number of years.

\section{Electronics Shop}

We observed a range of PPE usage in the electronics shop. While soldering, some electricians did not have on any PPE while others had on a combination of hearing protection (earmuffs), safety glasses, latex gloves, and R95 respirators. An electrician who sandblasted an aluminum sheet for five minutes was wearing a half-face respirator and safety glasses. However, the electrician was unshaven, did not have his respirator properly donned, and did not perform any seal checks prior to commencing sandblasting.

\section{Contactor Shop}

Employees in the contactor shop wore safety glasses when working and had respirators and gloves available in the shop. We did not observe any employees wearing gloves or respirators during our visit. Most employees wore latex gloves and safety glasses when handling dirty components. There was a glove box labeled "parts-washer" and we were informed that compressed air was used to clean parts. There was also a sonicating parts washer that was sometimes used by employees. We did not observe the compressed air cleaning process. 


\section{Tin Shop}

While grinding, punching holes, and drilling, employees in the tin shop wore safety glasses and gloves. Welders donned a face shield while welding. Tin smiths also spray-painted tin components, but their work area was not ventilated. The employee who did the spray painting did so with a fan blowing the paint back towards his person.

\section{Moving Trains in the Car Shop}

The Bug Guy was wearing an arc shield, hard hat, safety glasses, dust mask, steel-toed boots, long-sleeve shirt, and rubber electrical insulating gloves under leather gloves. The Bug Guy stood near the middle of the train car when applying the stinger and walked beside the train as it was moving. We observed three trains being moved during our visit. When the train cars become energized, there is a rush of air expelled from the train. We learned that employees in the car shop were concerned about exposures to the air released when trains were energized. The Bug Guy told us that the moves we observed were typical and that nothing unusual happened compared with when we were not at the facility.

\section{Methods: Exposure Assessment}

\section{Metals}

We collected full-shift personal air samples on employees from across the six shops on 2 days using 37-millimeter diameter, 0.8-micrometer pore-size, mixed cellulose ester filters and pumps calibrated at a flow rate of 2 liters per minute. We also took one short-term air sample (approximately 29 minutes) on an employee engaged in moving trains in the car shop.

- We analyzed each sample for aluminum, cadmium, chromium, cobalt, copper, iron, lead, magnesium, manganese, nickel, tin, titanium, and zinc using NIOSH Method 7303 [NIOSH 2021].

- We removed most of the full-shift air samplers from employees during their lunch break unless they stayed in the facility and did not request removal.

\section{Noise}

We were asked to assess the noise exposures in the electronics shop around the large heating, ventilation, and air-conditioning (HVAC) unit that was in the rear of the main shop. Spot measurements were made near the HVAC unit as well as at some nearby workstations. Measurements were also made in the truck, motor, tin, contactor, and wheel shops for short periods of time during different tasks. We used a calibrated, battery-operated, type-2 sound level meter for the sound measurements.

\section{Previous Exposure Monitoring}

The corporate safety office provided previous exposure monitoring reports. We reviewed select previous exposure monitoring reports to help understand past exposures and to determine which analytes we were going to sample for during our evaluation. 


\section{Results: Exposure Assessment}

\section{Metals}

The results for full-shift exposures to metals are shown in Tables C1-C6. All exposures were below the lowest occupational exposure limits (OELs). There were five samples in the tin shop and one sample in the electronics shop that were uninterpretable and were not included in the tables.

The results from the short-term personal sample is presented in Table C7. We found quantifiable levels of copper, iron oxide, manganese, and zinc oxide. We found detectable but not quantifiable levels of chromium, nickel, and titanium dioxide. We did not detect (ND) aluminum, cadmium, cobalt, lead, magnesium oxide, manganese, or tin. The results from this sample were well below the short-term exposure limits (STEL) for manganese and zinc oxide. We cannot compare the short-term sample to full-shift OELs since the sample did not cover the entire shift. However, we were told that train cars are not moved around for an entire shift. If the employee had been moving train cars for an entire shift and was exposed to the concentrations we found on the short-term sample, their exposures would be below the lowest OELs.

\section{Noise}

We took multiple area sound measurements while work was being performed in the different shops. All sound levels were measured in decibels and A-weighted (dBA). The measurements, tasks or locations, and distances from the task are presented in Table C8. Since these sound levels were not personal measurements, they cannot be directly compared to OELs. No tasks exceeded $140 \mathrm{dBA}$ at any time during our monitoring, although we saw some tasks that exceeded the NIOSH Recommended Exposure Limit (REL) of $85 \mathrm{dBA}$ and the OSHA Permissible Exposure Limit (PEL) of $90 \mathrm{dBA}$ for short durations.

\section{Previous Exposure Monitoring}

We reviewed a selection of previous sampling results from between 1999 and 2011. The only overexposure noted was for cadmium exposure in the contactor shop. In 2007, a single sample was above the OSHA Action Level (AL). We learned that sampling was repeated, and the overexposure was not detected a second time. The process for contactor maintenance was changed as described previously since these two sampling events were conducted. When reviewing previous noise sampling data, there were no overexposures noted. However, we noticed that the sampling was completed using OSHA criteria of a 5-dBA exchange rate, rather than the NIOSH or ACGIH 3-dBA exchange rate.

\section{Methods: Medical Survey and Reported PPE Use}

During the initial site visit we informally interviewed employees in each of the six shops to learn about their workplace health concerns. Employees reported concerns about dust most frequently, and some stated they had upper-respiratory symptoms. Based on those interviews and union and safety personnel input, we developed a survey that asked about work-related health concerns, medical diagnoses (including cancer), and use of respiratory and hearing protection. We also observed work practices during the first visit and decided to offer blood lead level (BLL) testing. We also asked specific lead-related health questions to electronic shop employees because of their exposure to lead.

\section{B-4}


We received a roster of all employees working in the designated shops prior to the second site visit to determine the schedule for administering the medical survey. Each employee working in those sections during our second site visit had the opportunity to complete the medical survey. Supervisors excused employees from their work area to visit with NIOSH medical staff. NIOSH staff explained the survey and answered any questions. If employees wanted to participate, they were given a hard copy of the survey to complete with NIOSH staff available to answer questions. Electronic shop employees had an extra section of the survey to complete regarding lead exposure and were also offered a BLL test. Informed consent was obtained for blood lead testing.

Survey questions included demographics, work activities, hearing and respiratory protection usage, work-related health concerns, and medical diagnoses. We asked specific close-ended questions about sinus problems, nasal symptoms (stuffy, itchy, or runny nose), eye symptoms (watery and itchy eyes), and trouble breathing within the last 12 months. We also asked close-ended questions about having a regular cough and hearing problems (ringing or buzzing in ears for 5 minutes or more a day). We included an open-ended question about what specifically aggravated their sinus, eye, and nasal symptoms at work. Additionally, we asked about medical conditions (recurrent sinusitis, recurrent upper respiratory infections, hearing loss, and cancer) diagnosed by a healthcare provider. NIOSH staff reviewed the surveys for completion and if an employee listed a cancer diagnosis, employees were asked to complete a medical record release for staff to possibly review medical records after the site visit. Because electronic shop employees used lead solder, we asked additional questions of these employees related to health symptoms they had experienced in the previous 3 months possibly caused by lead exposure. Once employees completed or declined the survey, they returned to their work area.

Data were entered into a database and analyzed using SAS 9.4 (Cary, NC).

\section{Results: Medical Survey and Reported PPE Use}

\section{Employees}

Of the 140 employees working in the designated shops during our second site visit, 126 (90\%) completed the medical survey. Employees had the option to not answer questions, which accounts for differing denominators, or percentages, on some reported results. Those who completed the survey were mostly male (98\%) and white (68\%) (Table C9). Forty-seven (38\%) employees had smoked cigarettes regularly throughout their lifetime, with 11 (23\%) of those employees reporting they were current smokers. Employees worked a median of 50 (range: 12-80) hours a week and had worked at this facility a median of 12 (range: $1-26)$ years. The job titles included electrician $(n=63)$, machinist $(\mathrm{n}=29)$, car repairman $(\mathrm{n}=18)$, oiler/laborer $(\mathrm{n}=4)$, gang foreman $(\mathrm{n}=4)$, and other $(\mathrm{n}=8)$. Employees from each of the six shops participated in this survey.

\section{Health Symptoms and Diagnoses}

Twenty-six (21\%) employees reported having a regular cough, and of those, $23(96 \%)$ reported work aggravated their cough (Table C10). Sixty-nine (55\%) employees reported having sinus problems, and $54(84 \%)$ of those employees reported work aggravated their sinus problems. Seventy-nine $(63 \%)$ employees reported having nasal symptoms, and 62 (79\%) employees reported work aggravated their nasal symptoms. Sixty-one (48\%) employees reported eye symptoms and 49 (84\%) reported that work aggravates their eye symptoms. Also, 34 (27\%) employees reported having trouble breathing, and

\section{B-5}


$69(59 \%)$ reported that their breathing is better while on vacation or not at work. Employees reported that they felt that dust, dirt, and inadequate ventilation contributed to their symptoms. Four employees also reported concerns related to VPI.

Thirty-seven (29\%) employees reported having hearing problems; of those employees, $23(66 \%)$ reported that they almost always experience those symptoms. Forty-six (37\%) employees reported it was difficult to follow a conversation if there is background noise. The tin shop had the highest proportion of employees who reported breathing problems, regular cough, nasal, sinus, and eye symptoms, and hearing problems.

Twenty-five (20\%) employees reported being diagnosed with recurrent sinusitis. Twenty (16\%) employees reported being diagnosed with recurrent upper-respiratory infections. Thirty (24\%) employees reported being diagnosed with hearing loss. Four (3\%) employees reported being diagnosed with cancer (testicular, kidney, acute lymphoblastic leukemia, and prostate).

\section{Hearing and Respiratory Protection Use}

Ninety-six employees $(76 \%)$ reported wearing hearing protection while working. Of those employees, $70(74 \%)$ reported wearing hearing protection (earplugs and/or earmuffs) for 4 hours or less during their shift, and $76(80 \%)$ reported wearing hearing protection for specific tasks. Eighty-seven (69\%) employees reported wearing respiratory protection (N95/R95 and/or elastomeric respirators). Of the employees who wore respiratory protection, (89\%) wore it for 4 hours or less during their shifts.

\section{Electronic Shop Employees}

Twenty-four electronics shop employees participated in the survey. When asked about health symptoms within the last 3 months, the most commonly reported symptoms were headaches (67\%), joint pain (57\%), tiredness (83\%), feeling irritable (57\%), and difficulty concentrating (52\%), with $16(67 \%)$ employees reporting at least three of those symptoms. Eight employees $(33 \%)$ reported having hobbies that also exposed them to lead, such as using firearms, renovating houses, and autobody work. Only four employees (17\%) reported receiving training about their lead exposure.

Nineteen $(79 \%)$ electronic shop employees consented to have a BLL drawn. Lead was not detected in three employees $(13 \%$ ), while the remainder of the employees had a median BLL of 0.995 (range: $0.52-2)$ micrograms per deciliter ( $\mu \mathrm{g} / \mathrm{dL})$.

\section{Discussion}

We did not identify any concerning exposures to metals or noise during this evaluation. Employees had access to PPE, though it was not always used, and we observed confusion among employees about the proper PPE ensembles needed for different situations. Although there were low exposure levels detected, opportunities exist for improved hygiene and hazard communication.

For example, employees were concerned about cadmium exposures in the contactor shop even though the process no longer exposes them to cadmium. Further, during both site visits, employees expressed their concerns about the VPI process; four employees reported those concerns during their medical survey. Employees were also concerned about potential exposures to the chemicals used in the VPI 
process even though the process has been outsourced and the equipment decommissioned. These are two opportunities where hazard communication between management and employees can be improved.

For both cadmium exposures and VPI-related exposures, there were multiple analytical reports provided to us from past sampling efforts. None showed the potential for overexposures to the chemicals used in the VPI process, and only a single sample for cadmium was over the OSHA AL. The single elevated cadmium exposure was detected before the process was changed to include enclosed contactors. In both of these examples, there is no evidence to suggest that there are potential overexposures.

More than half of the electronic shop employees reported headaches, joint pain, tiredness, irritability, and/or inability to concentrate. Although these symptoms can be related to lead exposure, they are generally nonspecific symptoms. A case of elevated BLL was defined as an employee with a BLL $\geq$ $5 \mu \mathrm{g} / \mathrm{dL}$. This definition is consistent with the current case definition used by NIOSH's Adult Blood Lead Epidemiology and Surveillance (ABLES) program, the Council of State and Territorial Epidemiologists (CSTE), and the Centers for Disease Control and Prevention (CDC) National Notifiable Diseases Surveillance System [CDC 2016, 2018; CSTE 2015]. All BLLs were within normal range making these reported symptoms not likely attributed to lead exposure.

Sampling efforts during this evaluation focused on first shift employees. Supervisors and employees informed us that work does not vary considerably within the same shop during different shifts. First shift had the most employees and the most work happening in the six shops that we evaluated. We were told that the only difference between shifts was that the overnight shift inspected trains in a shop not included in our evaluation. The findings and recommendations from this evaluation can be applied to second and third shift employees performing the same types of tasks in the shops that were evaluated.

While on site for this evaluation, unions reported an additional concern regarding possible metals exposures when trains were moved by the Bug Guy within the maintenance facility. This concern was not communicated to us by employees during our initial site visit. There were no metal-producing processes that occur regularly within this area of the facility. However, the short-term sample for metals in the breathing zone of an employee who was moving the trains showed all results were below applicable exposure limits. The employee told us that the trains moved during sampling were representative of the train moves that would occur during a typical shift.

The employee responsible for powering the trains when moving them stands very close to the air vents that power on when the train begins to move. These vents produce a visible cloud and are the most probable source of any inhaled metal exposures. Based on our results, there would be no overexposures to metals for this employee even if they had performed train moves continuously for an entire shift. Thus, we are confident that our results and observations are representative of the work being performed on all shifts in the six shops we evaluated, as well as the employees who perform train inspections.

One concern that was raised by multiple employees and unions concerned the lack of surface sampling performed during our evaluation. Employees told us that they were concerned about their exposures to visibly dirty surfaces in work areas as well as the ventilation ducts running across the ceiling of the facility. Surface sampling might help identify which analytes to target for air sampling, but there are no 
OELs for surface contamination. Personal air sampling is the gold standard for identifying and evaluating exposures in the workplace.

We were able to collect samples that were representative of the work performed in all shops that were included in our evaluation. The visible dust in work areas likely contains a mixture of metals from the work performed and dust from the outside getting in through the facility bay doors. We did not see any visible clouds of dust in any shop during our site visits. The visible accumulation on ducts and on top of equipment noted by employees takes a long time to build up and does not present a hazard if employees are not touching the dust and then subsequently performing hand to mouth activities (e.g., eating or smoking). Because there are still concerns about visible dust, hazard communication is important as is proper hand hygiene before breaks (e.g., bathroom, smoke, food) and before going home.

Employees in all shops most frequently reported sinus, nasal, and eye symptoms. These symptoms are also common allergy symptoms [Asthma and Allergy Foundation of America 2020]. In one study, $40 \%$ of the general population experienced at least one nasal allergy-like symptom in the past year, and $54 \%$ reported experiencing eye symptoms [Singh 2010]. The National Health Interview Survey (NHIS) also found that $6.7 \%$ of employed adults had allergy-like symptoms, and $10.2 \%$ of employed adults had sinusitis in 2018 [NHIS 2018]. Employees at this facility reported allergy-like symptoms more frequently than both of these representative studies. Interviews revealed that employees were concerned about dust and dirt throughout their work areas and attributed their allergy-like symptoms to the dust and dirt. We were told by employees and union representatives that there is time built into each shift to allow for cleaning of workstations as well as periodic deeper cleaning on a weekly or monthly basis. The reports of when cleaning was supposed to occur varied slightly from shop to shop but all shops agreed that there was time available to clean. We did not observe many cleaning activities during our visit.

Cleaning practices could be improved to make sure that each workstation is cleaned each day to prevent a build-up of contaminants. Daily cleaning would not be intensive and would remove visible dust and debris that had accumulated during the shift. Weekly or monthly periodic deep cleaning of workstations as well as the tops of equipment (e.g., cabinets, machines, tool chests) would prevent significant buildup of visible contamination on those surfaces. Reducing the amount of visible contamination combined with an effective hazard communication program would help address employee concerns about metals exposure.

We observed inconsistent PPE usage, and employees had difficulty explaining what PPE ensembles were required and why the components of the ensemble were important. Many employees had respirators available but told us that they did not visit the occupational health office to participate in the annual medical monitoring or fit testing as part of the respiratory protection program. Also, few employees in the electronic shop reported receiving training on lead exposure. The OSHA Hazard Communication standard [29 CFR 1910.1200] states that employers are required to provide "effective information and training" on workplace hazards upon initial assignment and when a new chemical is introduced into their work area [OSHA 2012]. Additionally, the OSHA Respiratory Protection standard [29 CFR 1910.134] has further requirements for respiratory protection programs, including medical clearance, training, and fit testing [OSHA 1998]. 
Occupational noise exposure limits are meant to be the amount of noise that most employees can be exposed to without substantial risk of hearing loss. The NIOSH REL for noise is $85 \mathrm{dBA}$ for an 8-hour work shift. The OSHA PEL for noise is $90 \mathrm{dBA}$, and the OSHA AL for noise is $85 \mathrm{dBA}$. Both OSHA limits are also for 8-hour work shifts.

Employers are required to keep noise exposures below the OSHA limits [29 CFR 1910.95]. However, NIOSH considers its noise exposure limit to be more protective. NIOSH and OSHA measure and calculate noise exposures in slightly different ways. For noise exposure measurements, NIOSH uses an $80 \mathrm{dBA}$ threshold and a 3-dB exchange rate. Noise below the threshold level is not integrated during measurements. The exchange rate expresses how much the sound level could increase or decrease while keeping the risk of hearing loss the same if the exposure duration was simultaneously decreased or increased. NIOSH considers noise measured using the $3-\mathrm{dB}$ exchange rate to more accurately relate noise exposures to hearing loss risk [NIOSH 1998]. Using this criterion, an employee can be exposed to $88 \mathrm{dBA}$ for no more than 4 hours, $91 \mathrm{dBA}$ for 2 hours, $94 \mathrm{dBA}$ for 1 hour, $97 \mathrm{dBA}$ for 0.5 hours, etc. For extended work shifts NIOSH adjusts the REL to $84.5 \mathrm{dBA}$ for a 9-hour shift, $84.0 \mathrm{dBA}$ for a 10-hour shift, 83.6 dBA for an 11-hour shift, and 83.2 dBA for a 12-hour work shift.

\section{Perceived Excess Cancer}

Cancers can appear to occur in clusters. Scientists define a cluster as a greater than expected number of cancer cases that occurs within a group of people in a geographic area over a defined period of time [CDC 2012]. A cluster may also be recognized when the cancers are found among employees of a different age group or sex than is usual. A statistically significant excess of cancer cases may have a common cause but can occur without a clear cause and can occur by chance [Aldrich and Sinks 2002; Thun and Sinks 2004]. For example, a confirmed cancer cluster could be the result of any of the following:

- Chance

- Miscalculation of the expected number of cancer cases (e.g., not considering a risk factor within the population at risk)

- Differences in the case definition between observed cases and expected cases

- Known causes of cancer (e.g., smoking)

- Unknown cause(s) of cancer [CDC 2012]

In many workplaces, the number of cases is small. This makes detecting whether the cases have a common cause difficult, especially when no apparent cancer-causing exposures are present. To assess whether the cancers among employees could be related to occupational exposures, many factors (occupational and nonoccupational) need to be considered, such as the likelihood of exposures to potential cancer-causing agents, timing of the diagnosis of cancer in relation to the exposure, and number and types of cancer cases. Because this information was not available from the unions or management for this health hazard evaluation (HHE), we administered a medical survey that included a question about cancer diagnoses. If an employee was diagnosed with cancer, we asked for the date of 
diagnosis, physician contact information, and a medical record release form to follow-up on diagnoses, if needed.

Of the 126 employees who completed the survey, 4 (3\%) employees reported cancer. All four employees were diagnosed with different types of cancers. These results were not consistent with the cancers being potentially caused by a work-related exposure. Below are two questions that relate to these cancer concerns:

\section{Do employees have an unusual distribution of types of cancer?}

We were only able to identify the diagnosis of four employees with different types of cancer. When several cases of the same type of cancer occur and that type is not common in the general population, it is more likely that an occupational exposure is involved. When a cluster consists of multiple types of cancer, then an occupational cause of the cluster is less likely.

\section{Do employees have more cancer than people who do not work at the facility?}

Because cancer is a common disease, cancer may be found among people at any workplace. When several cases of cancer occur in a workplace, they may be part of a true cluster when the number is greater than we expect compared to other groups of people similar in age, sex, and race. Disease or tumor rates, however, are highly variable in small populations and rarely match the overall rate for a larger area, such as the state, so that for any given time period some populations have rates above the overall rate and others have rates below the overall rate. Even when a higher rate occurs, it may be consistent with the expected random variability. In addition, calculations like this make many assumptions that may not be appropriate for every workplace. Comparing rates without adjusting for age, sex, or other population characteristics assumes that such characteristics are the same in the workplace as in the larger population, which may not be true. It is likely that more current and former employees have been diagnosed with cancer than those who were reported to us. As employees age, more cases of cancer will likely appear.

Both union and management representatives expressed continued concern about the perceived excess of cancer cases among employees and wanted to continue to evaluate whether employees were diagnosed with more cancer than the general population. To answer that question, it would require the calculation of rates of cancer types among employees during a defined period of time. This would require a large-scale epidemiologic study, which was not feasible through the HHE program. During our evaluation we spoke with a representative from Bureau of Environmental and Occupational Epidemiology at the New York State Health Department (NYSHD) regarding the cancer concerns. We referred management and union representatives to the NYSHD to follow up about the cancer concerns and informed the NYSHD that they may be contacted about this issue.

\section{Limitations}

This evaluation was subject to several limitations. Industrial hygiene sampling can only document exposures and conditions in the locations evaluated and on the days which the evaluation occurred. These results may not have been representative of conditions during other days. Medical questionnaires were also subject to similar limitations. We were only able to document concerns and symptoms that 
were reported to us during our evaluations by current employees who chose to participate. We were not able to include information from employees who had retired or otherwise left the work force.

To determine if an excess of cancer cases exists among all employees, conducting a large-scale epidemiologic study would be required; this is beyond the scope of the HHE program. However, the information we collected in our evaluation did not suggest the need for a larger scale study.

\section{Conclusions}

Our air sampling showed that there were no exposures to metals above relevant OELs; however, employees remained concerned about potential exposures to metals and dust. We found that training and hazard communication could be improved. We recommended expanded communication and training about exposures to metals, the VPI process, PPE, and cleaning and hygiene practices. Employees were also concerned about their health, specifically their respiratory health and a perceived excess risk of cancer. The results from our evaluation were not consistent with the reported cancers being caused by a work-related exposure. We were unable to evaluate whether there was an excess of cancer at this facility compared to the general population. Although we did not perform a large-scale epidemiologic study needed to address further cancer concerns, management and union representatives were referred to the state health department for assistance. We recommended that management improve communication about the actions taken and ongoing efforts related to the employees' health concerns. 


\section{Section C: Tables}

Table C1. Full-shift personal air sample results for metals in the truck shop $\left(\mu \mathrm{g} / \mathrm{m}^{3}\right)$

\begin{tabular}{|c|c|c|c|c|c|c|c|c|c|c|c|c|c|c|}
\hline \multirow[t]{2}{*}{ Job title } & \multicolumn{2}{|c|}{ Time (minutes) } & \multicolumn{2}{|c|}{ Aluminum } & \multicolumn{2}{|c|}{ Cadmium } & \multicolumn{2}{|c|}{ Chromium } & \multicolumn{2}{|c|}{ Cobalt } & \multicolumn{2}{|c|}{ Copper } & \multicolumn{2}{|c|}{ Iron oxide } \\
\hline & Day 1 & Day 2 & Day 1 & Day 2 & Day 1 & Day 2 & Day 1 & Day 2 & Day 1 & Day 2 & Day 1 & Day 2 & Day 1 & Day 2 \\
\hline Car repairman 1 & 325 & 344 & ND & ND & ND & ND & ND & ND & ND & ND & {$[0.17]$} & {$[0.13]$} & ND & 3.5 \\
\hline Car repairman 3 & 327 & - & ND & - & ND & - & ND & - & ND & - & 0.54 & - & 15 & - \\
\hline Car repairman 4 & - & 234 & - & ND & - & {$[0.07]$} & - & {$[0.28]$} & - & ND & - & {$[0.39]$} & - & 9.6 \\
\hline Electrician 2 & 258 & 343 & ND & ND & ND & {$[0.05]$} & ND & {$[0.16]$} & ND & ND & 1.9 & 0.78 & 23 & 52 \\
\hline Electrician 3 & 192 & 341 & ND & ND & ND & {$[0.05]$} & ND & {$[0.12]$} & {$[0.17]$} & ND & 0.99 & 0.91 & 23 & 15 \\
\hline Electrician 4 & - & 179 & - & ND & - & ND & - & {$[0.43]$} & - & ND & - & 2.6 & - & 68 \\
\hline Machinist 1 & 117 & 299 & ND & ND & ND & ND & ND & {$[0.15]$} & ND & ND & ND & {$[0.25]$} & 5.5 & 34 \\
\hline \multicolumn{3}{|l|}{ NIOSH REL } & \multicolumn{2}{|c|}{$10,000 / 5,000^{*}$} & \multicolumn{2}{|c|}{ Ca† } & \multicolumn{2}{|c|}{500} & \multicolumn{2}{|c|}{50} & \multicolumn{2}{|c|}{1,000} & \multicolumn{2}{|c|}{5,000} \\
\hline \multicolumn{3}{|c|}{ ACGIH threshold limit value (TLV) } & \multicolumn{2}{|c|}{$1,000 \ddagger$} & \multicolumn{2}{|c|}{$10 / 2^{*}$} & \multicolumn{2}{|c|}{500} & \multicolumn{2}{|c|}{20} & \multicolumn{2}{|c|}{1,000} & \multicolumn{2}{|c|}{$5,000 \ddagger$} \\
\hline \multicolumn{3}{|c|}{ Minimum detectable concentration§ } & \multicolumn{2}{|c|}{$0.8-3$} & \multicolumn{2}{|c|}{$0.04-0.1$} & 0.08 & -0.3 & 0.06 & -0.2 & 0.07 & -0.3 & & -2 \\
\hline Minimum quantifi & e conce & ration§ & & & 0.11 & 0.44 & 0.2 & -1.1 & 0.21 & 0.85 & 0.25 & -0.99 & 1.5 & -6.2 \\
\hline
\end{tabular}

[] Estimated concentration; this concentration was between the minimum detectable and minimum quantifiable concentrations.

* Total/respirable fraction

† Carcinogen: exposures to carcinogens should be kept as low as feasible.

$\ddagger$ Respirable fraction

$\S$ These values varied slightly from sample to sample. 
Table C1 (continued). Full-shift personal air sample results for metals in the truck shop $\left(\mu \mathrm{g} / \mathrm{m}^{3}\right)$

\begin{tabular}{|c|c|c|c|c|c|c|c|c|c|c|c|c|c|c|c|c|}
\hline \multirow[t]{2}{*}{ Job title } & \multicolumn{2}{|c|}{ Time (minutes) } & \multicolumn{2}{|c|}{ Lead } & \multicolumn{2}{|c|}{$\begin{array}{l}\text { Magnesium } \\
\text { oxide }\end{array}$} & \multicolumn{2}{|c|}{ Manganese } & \multicolumn{2}{|c|}{ Nickel } & \multicolumn{2}{|c|}{ Tin } & \multicolumn{2}{|c|}{$\begin{array}{l}\text { Titanium } \\
\text { dioxide }\end{array}$} & \multicolumn{2}{|c|}{ Zinc oxide } \\
\hline & Day 1 & Day 2 & Day 1 & Day 2 & Day 1 & Day 2 & Day 1 & Day 2 & Day 1 & Day 2 & Day 1 & Day 2 & Day 1 & Day 2 & Day 1 & Day 2 \\
\hline Car repairman 1 & 325 & 344 & ND & ND & ND & ND & ND & ND & ND & {$[0.05]$} & ND & ND & ND & ND & {$[0.04]$} & 0.22 \\
\hline Car repairman 2 & 359 & - & ND & - & ND & - & 0.6 & - & 0.95 & - & ND & - & {$[0.06]$} & - & 1.4 & - \\
\hline Car repairman 3 & 327 & - & ND & - & ND & - & 0.12 & - & ND & - & ND & - & {$[0.07]$} & - & 1.7 & - \\
\hline Car repairman 4 & - & 234 & - & ND & - & ND & - & {$[0.08]$} & - & {$[0.06]$} & - & ND & - & ND & - & 0.85 \\
\hline Car repairman 5 & - & 169 & - & ND & - & [0.09] & - & ND & - & [0.09] & - & ND & - & ND & - & 0.54 \\
\hline Electrician 1 & 233 & 164 & ND & [1] & ND & ND & [0.1] & 0.22 & [0.09] & [0.19] & ND & ND & ND & {$[0.11]$} & 0.71 & 2 \\
\hline Electrician 2 & 258 & 343 & {$[0.54]$} & ND & ND & ND & 1.7 & 0.4 & {$[0.06]$} & 0.19 & ND & ND & {$[0.07]$} & [0.09] & 1.5 & 1.1 \\
\hline Electrician 3 & 192 & 341 & ND & ND & ND & ND & 0.19 & 0.13 & ND & 0.1 & ND & ND & {$[0.08]$} & [0.08] & 4.4 & 1.4 \\
\hline Electrician 4 & - & 179 & - & ND & - & ND & - & 0.54 & - & {$[0.15]$} & - & ND & - & {$[0.14]$} & - & 6.5 \\
\hline Machinist 1 & 117 & 299 & ND & {$[0.54]$} & ND & ND & ND & 0.22 & ND & [0.08] & ND & ND & ND & ND & 0.36 & 0.36 \\
\hline Machinist 2 & - & 343 & - & ND & - & ND & - & ND & - & {$[0.06]$} & - & ND & - & ND & - & 0.24 \\
\hline Oiler 1 & 313 & - & ND & - & ND & - & [0.1] & - & ND & - & ND & - & {$[0.06]$} & - & 0.71 & - \\
\hline OSHA PEL & & & \multicolumn{2}{|c|}{50} & \multicolumn{2}{|c|}{15,000} & \multicolumn{2}{|c|}{$5,000 *$} & \multicolumn{2}{|c|}{1,000} & \multicolumn{2}{|c|}{2,000} & \multicolumn{2}{|c|}{15,000} & \multicolumn{2}{|c|}{5,000} \\
\hline NIOSH REL & & & \multicolumn{2}{|c|}{50} & \multicolumn{2}{|c|}{-} & \multicolumn{2}{|c|}{1,000} & \multicolumn{2}{|c|}{15} & \multicolumn{2}{|c|}{2,000} & \multicolumn{2}{|c|}{ Ca† } & \multicolumn{2}{|c|}{5,000} \\
\hline ACGIH TLV & & & \multicolumn{2}{|c|}{50} & \multicolumn{2}{|c|}{10,000} & \multicolumn{2}{|c|}{$100 / 20 \ddagger$} & \multicolumn{2}{|c|}{1,500} & \multicolumn{2}{|c|}{2,000} & \multicolumn{2}{|c|}{10,000} & \multicolumn{2}{|c|}{2,000} \\
\hline \multicolumn{3}{|c|}{ Minimum detectable concentration§ } & 0.2 & 0.9 & & & 0.02 & 0.09 & 0.02 & 0.09 & & & 0.04 & -0.1 & 0.02 & 0.09 \\
\hline Minimum quantifi & concer & ration§ & 0.9 & -3.7 & & & 0.078 & -0.31 & 0.076 & -0.30 & & & 0.12 & 0.46 & 0.096 & -0.38 \\
\hline
\end{tabular}

[ ] Estimated concentration; this concentration was between the minimum detectable and minimum quantifiable concentrations.

* Ceiling

† Carcinogen: exposures to carcinogens should be kept as low as feasible.

‡ Inhalable/respirable fraction

$\S$ These values varied slightly from sample to sample. 
Table C2. Full-shift personal air sample results for metals in the wheel shop $\left(\mu \mathrm{g} / \mathrm{m}^{3}\right)$

\begin{tabular}{|c|c|c|c|c|c|c|c|c|c|c|c|c|c|c|}
\hline \multirow[t]{2}{*}{ Job title } & \multicolumn{2}{|c|}{ Time (minutes) } & \multicolumn{2}{|c|}{ Aluminum } & \multicolumn{2}{|c|}{ Cadmium } & \multicolumn{2}{|c|}{ Chromium } & \multicolumn{2}{|c|}{ Cobalt } & \multicolumn{2}{|c|}{ Copper } & \multicolumn{2}{|c|}{ Iron oxide } \\
\hline & Day 1 & Day 2 & Day 1 & Day 2 & Day 1 & Day 2 & Day 1 & Day 2 & Day 1 & Day 2 & Day 1 & Day 2 & Day 1 & Day 2 \\
\hline Machinist 1 & 385 & 337 & ND & ND & ND & ND & ND & [0.12] & ND & ND & 0.29 & 0.66 & 5.9 & 10 \\
\hline Machinist 2 & 293 & - & ND & - & {$[0.1]$} & - & 2.7 & - & ND & - & 13 & - & 270 & - \\
\hline Machinist 3 & 369 & - & 11 & - & {$[0.1]$} & - & 0.57 & - & ND & - & 1.8 & - & 470 & - \\
\hline Machinist 4 & 340 & - & ND & - & ND & - & ND & - & ND & - & 0.6 & - & 8.7 & - \\
\hline Machinist 5 & 357 & - & ND & - & ND & - & ND & - & ND & - & [0.18] & - & 5 & - \\
\hline Machinist 6 & - & 107 & - & ND & - & ND & - & {$[0.76]$} & - & ND & - & 1 & - & 130 \\
\hline Machinist 7 & - & 246 & - & ND & - & {$[0.08]$} & - & ND & - & ND & - & {$[0.23]$} & - & 5.4 \\
\hline Machinist 8 & - & 354 & - & ND & - & {$[0.06]$} & - & {$[0.23]$} & - & ND & - & 0.54 & - & 7.9 \\
\hline Machinist 9 & - & 183 & - & ND & - & ND & - & ND & - & ND & - & 27 & - & 23 \\
\hline Machinist 10 & - & 345 & - & ND & - & ND & - & {$[0.16]$} & - & ND & - & 10 & - & 22 \\
\hline Oiler 1 & 240 & - & ND & - & ND & - & ND & - & ND & - & 1.8 & - & 9.6 & - \\
\hline OSHA PEL & & & \multicolumn{2}{|c|}{$15,000 / 5,000 *$} & \multicolumn{2}{|c|}{5} & \multicolumn{2}{|c|}{1,000} & \multicolumn{2}{|c|}{100} & \multicolumn{2}{|c|}{1,000} & \multicolumn{2}{|c|}{10,000} \\
\hline NIOSH REL & & & \multicolumn{2}{|c|}{$10,000 / 5,000^{*}$} & \multicolumn{2}{|c|}{ Cat } & \multicolumn{2}{|c|}{500} & \multicolumn{2}{|c|}{50} & \multicolumn{2}{|c|}{1,000} & \multicolumn{2}{|c|}{5,000} \\
\hline ACGIH TLV & & & \multicolumn{2}{|c|}{$1,000 \ddagger$} & \multicolumn{2}{|c|}{$10 / 2^{*}$} & \multicolumn{2}{|c|}{500} & \multicolumn{2}{|c|}{20} & \multicolumn{2}{|c|}{1,000} & \multicolumn{2}{|c|}{$5,000 \ddagger$} \\
\hline \multicolumn{3}{|c|}{ Minimum detectable concentration§ } & \multicolumn{2}{|c|}{$0.8-3$} & \multicolumn{2}{|c|}{$0.04-0.1$} & \multicolumn{2}{|c|}{$0.08-0.3$} & \multicolumn{2}{|c|}{$0.06-0.2$} & \multicolumn{2}{|c|}{$0.07-0.3$} & \multicolumn{2}{|c|}{$0.5-2$} \\
\hline Minimum qua & oncentr & & & & 0.11 & .44 & 0.2 & 1.1 & 0.21 & 0.85 & 0.25 & 0.99 & & 6.2 \\
\hline
\end{tabular}

[ ] Estimated concentration; this concentration was between the minimum detectable and minimum quantifiable concentrations.

* Total/respirable fraction

† Carcinogen: Exposures to carcinogens should be kept as low as feasible.

‡ Respirable fraction

$\S$ These values varied slightly from sample to sample. 
Table C2 (continued). Full-shift personal air sample results for metals in the wheel shop $\left(\mu \mathrm{g} / \mathrm{m}^{3}\right)$

\begin{tabular}{|c|c|c|c|c|c|c|c|c|c|c|c|c|c|c|c|c|}
\hline \multirow[t]{2}{*}{ Job title } & \multicolumn{2}{|c|}{ Time (minutes) } & \multicolumn{2}{|c|}{ Lead } & \multicolumn{2}{|c|}{$\begin{array}{l}\text { Magnesium } \\
\text { oxide }\end{array}$} & \multicolumn{2}{|c|}{ Manganese } & \multicolumn{2}{|c|}{ Nickel } & \multicolumn{2}{|c|}{ Tin } & \multicolumn{2}{|c|}{$\begin{array}{l}\text { Titanium } \\
\text { dioxide }\end{array}$} & \multicolumn{2}{|c|}{ Zinc oxide } \\
\hline & Day 1 & Day 2 & Day 1 & Day 2 & Day 1 & Day 2 & Day 1 & Day 2 & Day 1 & Day 2 & Day 1 & Day 2 & Day 1 & Day 2 & Day 1 & Day 2 \\
\hline Machinist 1 & 385 & 337 & {$[0.33]$} & ND & ND & ND & {$[0.04]$} & {$[0.08]$} & {$[0.04]$} & {$[0.06]$} & ND & ND & ND & ND & 0.17 & 0.54 \\
\hline Machinist 2 & 293 & - & 1.9 & - & ND & - & 2.4 & - & 0.34 & - & ND & - & {$[0.09]$} & - & 1.7 & - \\
\hline Machinist 3 & 369 & - & ND & - & ND & - & 5.1 & - & 0.44 & - & ND & - & 0.65 & - & 0.8 & - \\
\hline Machinist 4 & 340 & - & ND & - & ND & - & [0.07] & - & ND & - & {$[0.82]$} & - & {$[0.06]$} & - & 0.34 & - \\
\hline Machinist 5 & 357 & - & ND & - & ND & - & [0.04] & - & ND & - & ND & - & ND & - & ND & - \\
\hline Machinist 6 & - & 107 & - & ND & - & ND & - & 0.9 & - & 0.52 & - & ND & - & ND & - & 0.66 \\
\hline Machinist 7 & - & 246 & - & ND & - & ND & - & ND & - & {$[0.12]$} & - & ND & - & ND & - & ND \\
\hline Machinist 8 & - & 354 & - & ND & - & ND & - & 0.1 & - & 0.1 & - & ND & - & ND & - & 0.33 \\
\hline Machinist 9 & - & 183 & - & {$[0.97]$} & - & ND & - & {$[0.17]$} & - & 0.22 & - & 1.8 & - & ND & - & 5 \\
\hline Machinist 10 & - & 345 & - & {$[0.06]$} & - & ND & - & 0.18 & - & 0.10 & - & {$[0.68]$} & - & {$[0.05]$} & - & 6.2 \\
\hline Oiler 1 & 240 & - & ND & - & ND & - & [0.09] & - & ND & - & ND & - & ND & - & 0.35 & - \\
\hline \multicolumn{3}{|l|}{ OSHA PEL } & \multicolumn{2}{|c|}{50} & \multicolumn{2}{|c|}{15,000} & \multicolumn{2}{|c|}{$5,000^{*}$} & \multicolumn{2}{|c|}{1,000} & \multicolumn{2}{|c|}{2,000} & \multicolumn{2}{|c|}{15,000} & \multicolumn{2}{|c|}{5,000} \\
\hline NIOSH REL & & & \multicolumn{2}{|c|}{50} & \multicolumn{2}{|c|}{-} & \multicolumn{2}{|c|}{1,000} & \multicolumn{2}{|c|}{15} & \multicolumn{2}{|c|}{2,000} & \multicolumn{2}{|c|}{ Ca† } & \multicolumn{2}{|c|}{5,000} \\
\hline ACGIH TLV & & & \multicolumn{2}{|c|}{50} & \multicolumn{2}{|c|}{10,000} & \multicolumn{2}{|c|}{$100 / 20 \ddagger$} & \multicolumn{2}{|c|}{1,500} & \multicolumn{2}{|c|}{2,000} & \multicolumn{2}{|c|}{10,000} & \multicolumn{2}{|c|}{2,000} \\
\hline \multicolumn{3}{|c|}{ Minimum detectable concentration§ } & 0.2 & -0.9 & & & 0.02 & 0.09 & 0.02 & 0.09 & 0. & & 0.04 & -0.1 & 0.02 & 0.09 \\
\hline Minimum qua & concer & ration§ & 0.9 & -3.7 & & 41 & 0.078 & -0.31 & 0.076 & -0.30 & $1-$ & & 0.12 & -0.46 & 0.09 & -0.38 \\
\hline
\end{tabular}

[ ] Estimated concentration; this concentration was between the minimum detectable and minimum quantifiable concentrations.

* Ceiling

† Carcinogen: exposures to carcinogens should be kept as low as feasible.

‡ Inhalable/respirable fraction

$\S$ These values varied slightly from sample to sample. 
Table C3. Full-shift personal air sample results for metals in the motor shop $\left(\mu \mathrm{g} / \mathrm{m}^{3}\right)$

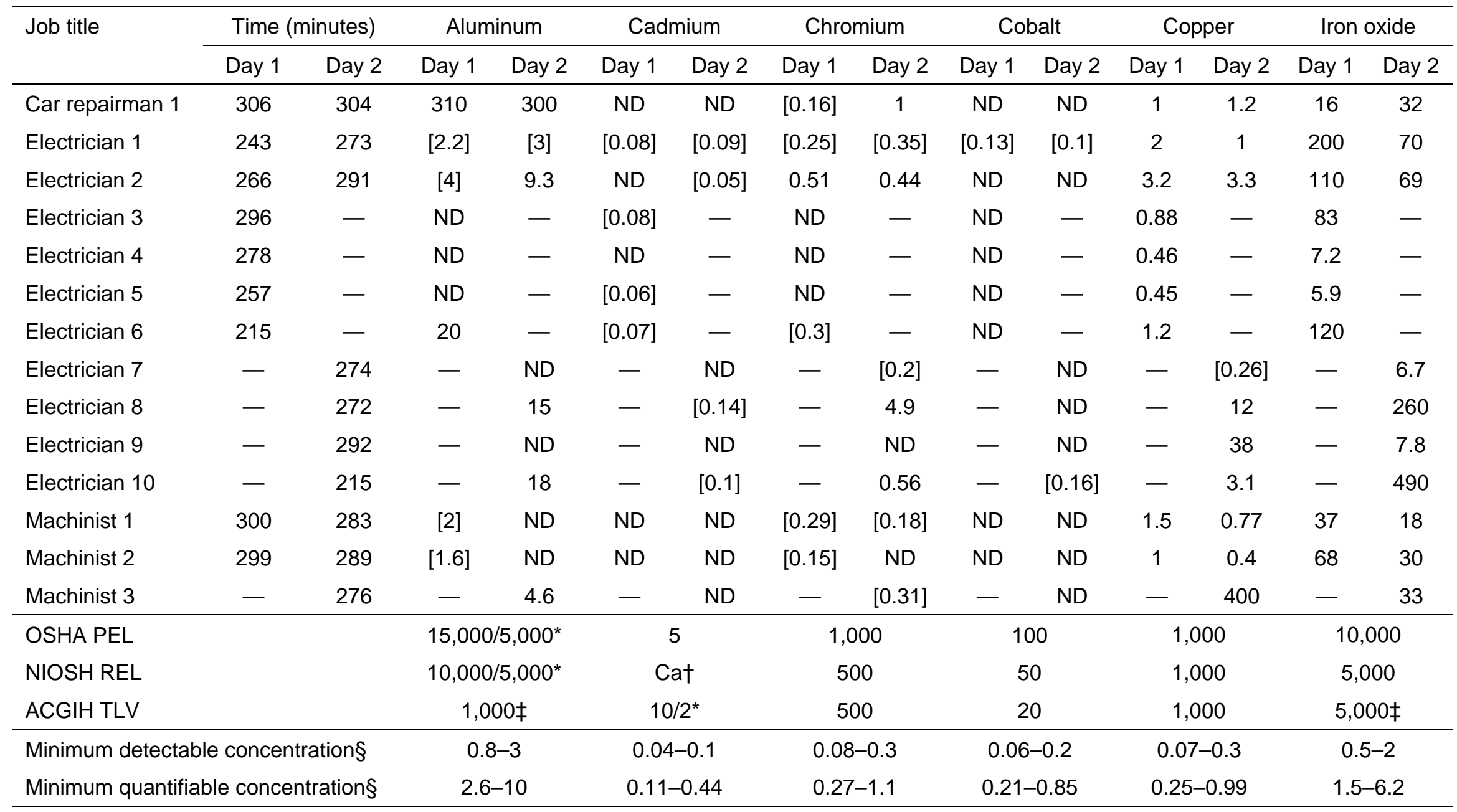

[] Estimated concentration; this concentration was between the minimum detectable and minimum quantifiable concentrations.

* Total/respirable fraction

† Carcinogen: exposures to carcinogens should be kept as low as feasible.

$\ddagger$ Respirable fraction

$\S$ These values varied slightly from sample to sample. 
Table C3 (continued). Full-shift personal air sample results for metals in the motor shop $\left(\mu \mathrm{g} / \mathrm{m}^{3}\right)$

\begin{tabular}{|c|c|c|c|c|c|c|c|c|c|c|c|c|c|c|c|c|}
\hline \multirow[t]{2}{*}{ Job title } & \multicolumn{2}{|c|}{ Time (minutes) } & \multicolumn{2}{|c|}{ Lead } & \multicolumn{2}{|c|}{$\begin{array}{l}\text { Magnesium } \\
\text { oxide }\end{array}$} & \multicolumn{2}{|c|}{ Manganese } & \multicolumn{2}{|c|}{ Nickel } & \multicolumn{2}{|c|}{ Tin } & \multicolumn{2}{|c|}{$\begin{array}{l}\text { Titanium } \\
\text { dioxide }\end{array}$} & \multicolumn{2}{|c|}{ Zinc oxide } \\
\hline & Day 1 & Day 2 & Day 1 & Day 2 & Day 1 & Day 2 & Day 1 & Day 2 & Day 1 & Day 2 & Day 1 & Day 2 & Day 1 & Day 2 & Day 1 & Day 2 \\
\hline Car repairman 1 & 306 & 304 & {$[0.39]$} & ND & ND & ND & 0.26 & 1.3 & 1 & 1.5 & 1.8 & ND & 0.24 & 0.3 & 1.1 & 0.67 \\
\hline Electrician 1 & 243 & 273 & {$[0.51]$} & ND & [6.3] & ND & 1.2 & 0.31 & {$[0.06]$} & 0.12 & [1.3] & ND & {$[0.15]$} & ND & 9.4 & 5.2 \\
\hline Electrician 2 & 266 & 291 & {$[0.5]$} & {$[0.55]$} & ND & ND & 0.9 & 0.47 & 0.38 & 0.18 & ND & ND & 0.21 & {$[0.14]$} & 5.3 & 11 \\
\hline Electrician 3 & 296 & - & {$[0.78]$} & - & ND & - & 0.44 & - & 0.11 & - & 2.4 & - & {$[0.06]$} & - & 1.6 & - \\
\hline Electrician 4 & 278 & - & {$[0.76]$} & - & ND & - & {$[0.04]$} & - & [0.05] & - & {$[1.2]$} & - & ND & - & 0.29 & - \\
\hline Electrician 5 & 257 & - & ND & - & ND & - & {$[0.04]$} & - & {$[0.04]$} & - & ND & - & ND & - & 0.43 & - \\
\hline Electrician 6 & 215 & - & ND & - & ND & - & 0.77 & - & {$[0.14]$} & - & ND & - & {$[0.14]$} & - & 2.6 & - \\
\hline Electrician 7 & - & 274 & - & ND & - & ND & - & {$[0.05]$} & - & 0.2 & - & ND & - & ND & - & 0.24 \\
\hline Electrician 8 & - & 272 & - & [1.1] & - & [8.1] & - & 2.1 & - & 2.6 & - & {$[0.72]$} & - & 0.53 & - & 9.6 \\
\hline Electrician 9 & - & 292 & - & ND & - & ND & - & 2.1 & - & {$[0.1]$} & - & ND & - & ND & - & 0.45 \\
\hline Electrician 10 & - & 215 & - & ND & - & ND & - & 3.3 & - & 0.82 & - & ND & - & 0.38 & - & 4 \\
\hline Machinist 1 & 300 & 283 & ND & ND & ND & ND & 0.3 & 0.13 & 0.17 & {$[0.06]$} & {$[0.57]$} & ND & {$[0.1]$} & {$[0.07]$} & 6.6 & 0.7 \\
\hline Machinist 2 & 299 & 289 & ND & ND & ND & ND & 0.61 & 0.31 & ND & 0.18 & {$[0.7]$} & {$[0.72]$} & {$[0.07]$} & ND & 2.4 & 4 \\
\hline Machinist 3 & - & 276 & - & {$[0.79]$} & - & ND & - & 0.26 & - & [0.12] & - & ND & - & ND & - & 1.8 \\
\hline OSHA PEL & & & \multicolumn{2}{|c|}{50} & \multicolumn{2}{|c|}{15,000} & \multicolumn{2}{|c|}{$5,000 *$} & \multicolumn{2}{|c|}{1,000} & \multicolumn{2}{|c|}{2,000} & \multicolumn{2}{|c|}{15,000} & \multicolumn{2}{|c|}{5,000} \\
\hline NIOSH REL & & & \multicolumn{2}{|c|}{50} & \multicolumn{2}{|c|}{ - } & \multicolumn{2}{|c|}{1,000} & \multicolumn{2}{|c|}{15} & \multicolumn{2}{|c|}{2,000} & \multicolumn{2}{|c|}{ Ca† } & \multicolumn{2}{|c|}{5,000} \\
\hline ACGIH TLV & & & \multicolumn{2}{|c|}{50} & \multicolumn{2}{|c|}{10,000} & \multicolumn{2}{|c|}{$100 / 20 \ddagger$} & \multicolumn{2}{|c|}{1,500} & \multicolumn{2}{|c|}{2,000} & \multicolumn{2}{|c|}{10,000} & \multicolumn{2}{|c|}{2,000} \\
\hline Minimum detecta & concen & ation§ & 0.2 & 0.9 & & & 0.02 & 0.09 & 0.02 & 0.09 & & & 0.0 & -0.1 & 0.02 & -0.09 \\
\hline Minimum quantifi & concer & ration§ & 0.9 & -3.7 & & & 0.078 & -0.31 & 0.076 & -0.30 & & & 0.12 & 0.46 & 0.09 & -0.38 \\
\hline
\end{tabular}

[ ] Estimated concentration; this concentration was between the minimum detectable and minimum quantifiable concentrations.

* Ceiling

† Carcinogen: exposures to carcinogens should be kept as low as feasible.

$\ddagger$ Inhalable/respirable fraction

$\S$ These values varied slightly from sample to sample. 
Table C4. Full-shift personal air sample results for metals in the electronics shop $\left(\mu \mathrm{g} / \mathrm{m}^{3}\right)$

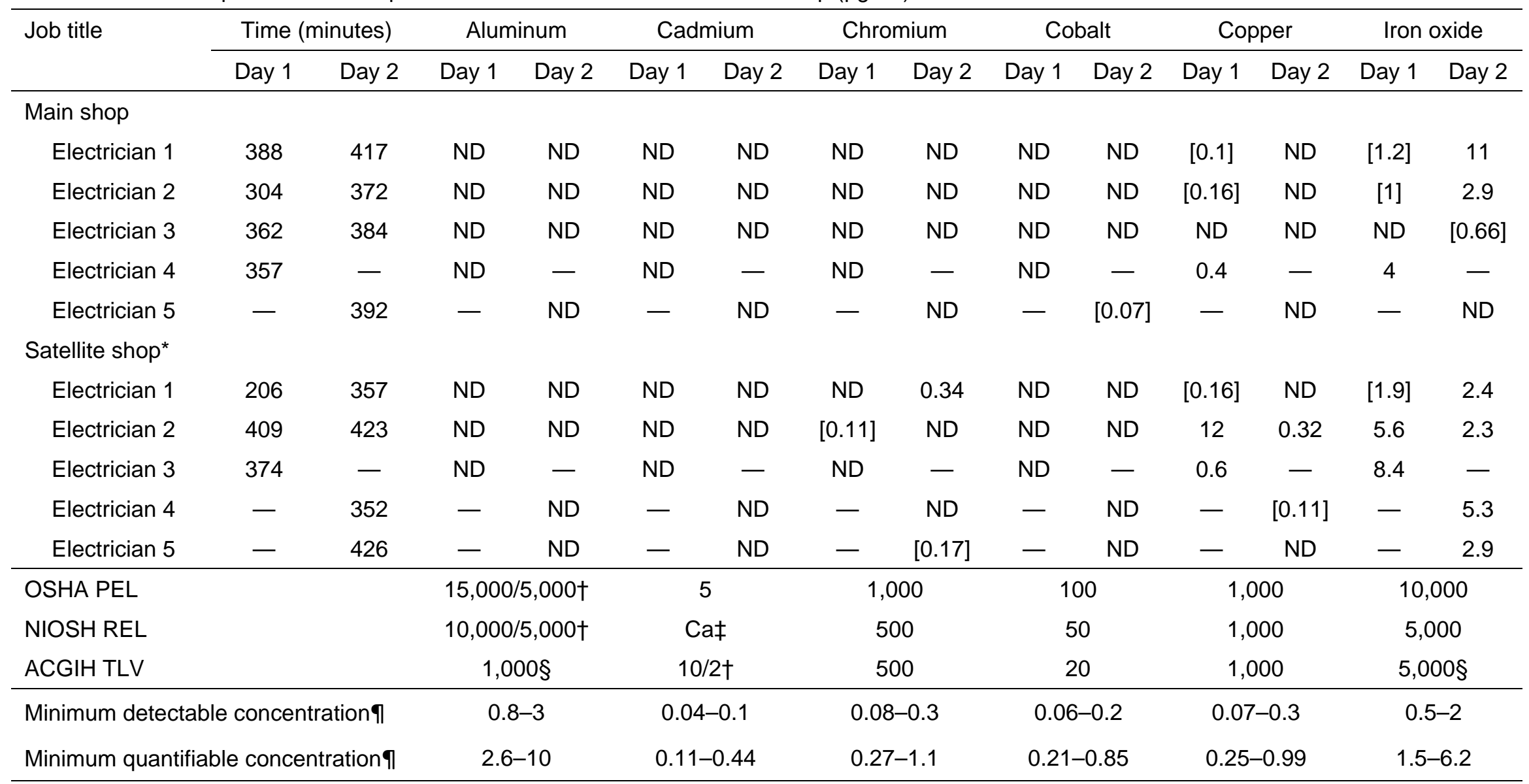

[ ] Estimated concentration; this concentration was between the minimum detectable and minimum quantifiable concentrations.

* Data from one electrician in the satellite shop is not presented because the data was uninterpretable.

$\dagger$ Total/respirable fraction

‡ Carcinogen: exposures to carcinogens should be kept as low as feasible.

$\S$ Respirable fraction

I These values varied slightly from sample to sample. 
Table C4 (continued). Full-shift personal air sample results for metals in the electronics shop $\left(\mu \mathrm{g} / \mathrm{m}^{3}\right)$

\begin{tabular}{|c|c|c|c|c|c|c|c|c|c|c|c|c|c|c|c|c|}
\hline \multirow[t]{2}{*}{ Job title } & \multicolumn{2}{|c|}{ Time (minutes) } & \multicolumn{2}{|c|}{ Lead } & \multicolumn{2}{|c|}{$\begin{array}{l}\text { Magnesium } \\
\text { oxide }\end{array}$} & \multicolumn{2}{|c|}{ Manganese } & \multicolumn{2}{|c|}{ Nickel } & \multicolumn{2}{|c|}{ Tin } & \multicolumn{2}{|c|}{$\begin{array}{l}\text { Titanium } \\
\text { dioxide }\end{array}$} & \multicolumn{2}{|c|}{ Zinc oxide } \\
\hline & Day 1 & Day 2 & Day 1 & Day 2 & Day 1 & Day 2 & Day 1 & Day 2 & Day 1 & Day 2 & Day 1 & Day 2 & Day 1 & Day 2 & Day 1 & Day 2 \\
\hline \multicolumn{17}{|l|}{ Main shop } \\
\hline Electrician 1 & 388 & 417 & {$[0.67]$} & ND & ND & ND & ND & {$[0.05]$} & ND & {$[0.04]$} & 1.8 & ND & ND & ND & 0.95 & [0.08] \\
\hline Electrician 2 & 304 & 372 & 11 & ND & ND & ND & ND & ND & ND & 0.1 & 16 & [0.49] & ND & ND & 0.29 & 0.2 \\
\hline Electrician 3 & 362 & 384 & ND & ND & ND & ND & ND & ND & ND & ND & ND & ND & ND & ND & 0.5 & [0.09] \\
\hline Electrician 4 & 357 & - & 12 & - & ND & - & ND & - & {$[0.05]$} & - & 13 & - & ND & - & 0.18 & - \\
\hline Electrician 5 & - & 392 & - & ND & - & ND & - & ND & - & ND & - & ND & - & ND & - & {$[0.05]$} \\
\hline \multicolumn{17}{|l|}{ Satellite shop* } \\
\hline Electrician 1 & 206 & 357 & {$[1.6]$} & ND & ND & ND & ND & ND & ND & 0.18 & {$[1.7]$} & ND & ND & ND & 1.8 & [0.09] \\
\hline Electrician 2 & 409 & 423 & 22 & ND & ND & ND & {$[0.03]$} & ND & {$[0.03]$} & ND & 40 & ND & ND & ND & 3.9 & 0.23 \\
\hline Electrician 3 & 374 & - & 7.1 & - & ND & - & {$[0.06]$} & - & ND & - & 12 & - & ND & - & 0.72 & - \\
\hline Electrician 4 & - & 352 & - & {$[0.39]$} & - & ND & - & ND & - & ND & - & ND & - & ND & - & 0.24 \\
\hline Electrician 5 & - & 426 & - & ND & - & ND & - & ND & - & 0.15 & - & ND & - & ND & - & {$[0.06]$} \\
\hline OSHA PEL & & & \multicolumn{2}{|c|}{50} & \multicolumn{2}{|c|}{15,000} & \multicolumn{2}{|c|}{$5,000 \dagger$} & \multicolumn{2}{|c|}{1,000} & \multicolumn{2}{|c|}{2,000} & \multicolumn{2}{|c|}{15,000} & \multicolumn{2}{|c|}{5,000} \\
\hline NIOSH REL & & & \multicolumn{2}{|c|}{50} & \multicolumn{2}{|c|}{-} & \multicolumn{2}{|c|}{1,000} & \multicolumn{2}{|c|}{15} & \multicolumn{2}{|c|}{2,000} & \multicolumn{2}{|c|}{ Cał } & \multicolumn{2}{|c|}{5,000} \\
\hline ACGIH TLV & & & \multicolumn{2}{|c|}{50} & \multicolumn{2}{|c|}{10,000} & \multicolumn{2}{|c|}{$100 / 20 \S$} & \multicolumn{2}{|c|}{1,500} & \multicolumn{2}{|c|}{2,000} & \multicolumn{2}{|c|}{10,000} & & \\
\hline Minimum detecta & concen & ation & 0.2 & -0.9 & & & 0.02 & 0.09 & 0.02 & 0.09 & & & 0.04 & -0.1 & 0.02 & 0.09 \\
\hline Minimum quantif & le conce & rationף & 0.94 & -3.7 & & 41 & $0.07 \varepsilon$ & -0.31 & 0.076 & -0.30 & & & 0.12 & 0.46 & 0.096 & -0.38 \\
\hline
\end{tabular}

[ ] Estimated concentration; this concentration was between the minimum detectable and minimum quantifiable concentrations.

* Data from one electrician in the satellite shop is not presented because the data was uninterpretable.

$\dagger$ Ceiling

‡ Carcinogen: exposures to carcinogens should be kept as low as feasible.

$\S$ Inhalable/respirable fraction

I These values varied slightly from sample to sample. The most conservative numbers are listed here. 
Table C5. Full-shift air sample results for metals in the contactor shop $\left(\mu \mathrm{g} / \mathrm{m}^{3}\right)$

\begin{tabular}{|c|c|c|c|c|c|c|c|c|c|c|c|c|c|c|}
\hline \multirow[t]{2}{*}{ Job title } & \multicolumn{2}{|c|}{ Time (minutes) } & \multicolumn{2}{|c|}{ Aluminum } & \multicolumn{2}{|c|}{ Cadmium } & \multicolumn{2}{|c|}{ Chromium } & \multicolumn{2}{|c|}{ Cobalt } & \multicolumn{2}{|c|}{ Copper } & \multicolumn{2}{|c|}{ Iron oxide } \\
\hline & Day 1 & Day 2 & Day 1 & Day 2 & Day 1 & Day 2 & Day 1 & Day 2 & Day 1 & Day 2 & Day 1 & Day 2 & Day 1 & Day 2 \\
\hline Electrician 1 & 267 & 328 & ND & ND & {$[0.07]$} & ND & ND & {$[0.11]$} & ND & ND & {$[0.21]$} & {$[0.28]$} & 4.1 & 9.7 \\
\hline Electrician 2 & 324 & - & ND & - & ND & - & ND & - & ND & - & 0.51 & - & 7.7 & - \\
\hline Electrician 3 & 369 & - & ND & - & ND & - & ND & - & ND & - & 0.73 & - & 27 & - \\
\hline Electrician 4 & 359 & - & ND & - & ND & - & ND & - & ND & - & 0.4 & - & 2.6 & - \\
\hline Electrician 5 & - & 340 & - & ND & - & ND & - & ND & - & ND & - & ND & - & [1.9] \\
\hline Electrician 6 & - & 372 & - & ND & - & ND & - & {$[0.29]$} & - & ND & - & {$[0.18]$} & - & 6.5 \\
\hline Workstation* & - & 115 & - & ND & - & {$[0.17]$} & - & ND & - & ND & - & ND & - & 39 \\
\hline M3 coupler repair* & - & 376 & - & ND & - & ND & - & ND & - & ND & - & {$[0.23]$} & - & 4.8 \\
\hline Opening train parts* & 一 & 350 & - & 30 & - & {$[0.17]$} & 一 & 2.1 & - & {$[0.04]$} & - & 9 & - & 400 \\
\hline OSHA PEL & & & \multicolumn{2}{|c|}{$15,000 / 5,000 \dagger$} & \multicolumn{2}{|c|}{5} & \multicolumn{2}{|c|}{1,000} & \multicolumn{2}{|c|}{100} & \multicolumn{2}{|c|}{1,000} & \multicolumn{2}{|c|}{10,000} \\
\hline NIOSH REL & & & \multicolumn{2}{|c|}{$10,000 / 5,000 \dagger$} & \multicolumn{2}{|c|}{ Cał } & \multicolumn{2}{|c|}{500} & \multicolumn{2}{|c|}{50} & \multicolumn{2}{|c|}{1,000} & \multicolumn{2}{|c|}{5,000} \\
\hline ACGIH TLV & & & \multicolumn{2}{|c|}{$1,000 \S$} & \multicolumn{2}{|c|}{$10 / 2 \dagger$} & \multicolumn{2}{|c|}{500} & \multicolumn{2}{|c|}{20} & \multicolumn{2}{|c|}{1,000} & \multicolumn{2}{|c|}{$5,000 \S$} \\
\hline Minimum detectable & htration & & \multicolumn{2}{|c|}{$0.8-3$} & \multicolumn{2}{|c|}{$0.04-0.1$} & \multicolumn{2}{|c|}{$0.08-0.3$} & \multicolumn{2}{|c|}{$0.06-0.2$} & \multicolumn{2}{|c|}{$0.07-0.3$} & \multicolumn{2}{|c|}{$0.5-2$} \\
\hline Minimum quantifiable & centratio & & \multicolumn{2}{|c|}{$2.6-10$} & \multicolumn{2}{|c|}{$0.11-0.44$} & 0.2 & 1.1 & 0.21 & 0.85 & 0.25 & 0.99 & 1.5 & -6.2 \\
\hline
\end{tabular}

[ ] Estimated concentration; this concentration was between the minimum detectable and minimum quantifiable concentrations.

* Area sample

$\dagger$ Total/respirable fraction

‡ Carcinogen: exposures to carcinogens should be kept as low as feasible.

$\S$ Respirable fraction

I These values varied slightly from sample to sample. 
Table C5 (continued). Full-shift air sample results for metals in the contactor shop $\left(\mu \mathrm{g} / \mathrm{m}^{3}\right)$

\begin{tabular}{|c|c|c|c|c|c|c|c|c|c|c|c|c|c|c|c|c|}
\hline \multirow[t]{2}{*}{ Job title } & \multicolumn{2}{|c|}{ Time (minutes) } & \multicolumn{2}{|c|}{ Lead } & \multicolumn{2}{|c|}{$\begin{array}{l}\text { Magnesium } \\
\text { oxide }\end{array}$} & \multicolumn{2}{|c|}{ Manganese } & \multicolumn{2}{|c|}{ Nickel } & \multicolumn{2}{|c|}{ Tin } & \multicolumn{2}{|c|}{$\begin{array}{l}\text { Titanium } \\
\text { dioxide }\end{array}$} & \multicolumn{2}{|c|}{ Zinc oxide } \\
\hline & Day 1 & Day 2 & Day 1 & Day 2 & Day 1 & Day 2 & Day 1 & Day 2 & Day 1 & Day 2 & Day 1 & Day 2 & Day 1 & Day 2 & Day 1 & Day 2 \\
\hline Electrician 1 & 267 & 328 & ND & {$[0.34]$} & ND & ND & ND & {$[0.08]$} & ND & {$[0.09]$} & {$[0.73]$} & ND & ND & ND & 1.1 & 0.29 \\
\hline Electrician 2 & 324 & - & {$[0.31]$} & - & ND & - & {$[0.05]$} & - & ND & - & ND & - & ND & - & 0.78 & - \\
\hline Electrician 3 & 369 & - & [0.99] & - & ND & - & 0.2 & - & {$[0.07]$} & - & 5.5 & - & {$[0.11]$} & - & 1 & - \\
\hline Electrician 4 & 359 & - & {$[0.5]$} & - & ND & - & ND & - & {$[0.05]$} & - & {$[0.65]$} & - & ND & - & 1.2 & - \\
\hline Electrician 5 & - & 340 & - & ND & - & ND & - & {$[0.07]$} & - & ND & - & ND & - & ND & - & {$[0.06]$} \\
\hline Electrician 6 & - & 372 & - & ND & - & ND & - & {$[0.06]$} & - & 0.16 & - & ND & - & ND & - & 0.16 \\
\hline Workstation* & - & 115 & - & {$[1.8]$} & - & ND & - & {$[0.2]$} & - & {$[0.13]$} & - & {$[2.2]$} & - & ND & - & {$[0.15]$} \\
\hline M3 coupler repair* & - & 376 & - & ND & - & ND & - & {$[0.03]$} & - & ND & - & ND & - & ND & - & 0.44 \\
\hline Opening train parts* & - & 350 & - & {$[0.8]$} & - & [14] & - & 3.2 & - & 0.99 & - & 2.3 & - & 1.2 & - & 4.3 \\
\hline \multicolumn{3}{|l|}{ OSHA PEL } & \multicolumn{2}{|c|}{50} & \multicolumn{2}{|c|}{15,000} & \multicolumn{2}{|c|}{$5,000 \dagger$} & \multicolumn{2}{|c|}{1,000} & \multicolumn{2}{|c|}{2,000} & \multicolumn{2}{|c|}{15,000} & \multicolumn{2}{|c|}{5,000} \\
\hline NIOSH REL & & & \multicolumn{2}{|c|}{50} & \multicolumn{2}{|c|}{-} & \multicolumn{2}{|c|}{1,000} & \multicolumn{2}{|c|}{15} & \multicolumn{2}{|c|}{2,000} & \multicolumn{2}{|c|}{ Caf } & \multicolumn{2}{|c|}{5,000} \\
\hline ACGIH TLV & & & \multicolumn{2}{|c|}{50} & \multicolumn{2}{|c|}{10,000} & \multicolumn{2}{|c|}{$100 / 20 \S$} & \multicolumn{2}{|c|}{1,500} & \multicolumn{2}{|c|}{2,000} & \multicolumn{2}{|c|}{10,000} & \multicolumn{2}{|c|}{2,000} \\
\hline \multicolumn{3}{|c|}{ Minimum detectable concentration $\uparrow$} & \multicolumn{2}{|c|}{$0.2-0.9$} & & & $0.02-$ & 0.09 & 0.02 & 0.09 & 0.4 & -1 & 0.04 & -0.1 & 0.02 & -0.09 \\
\hline Minimum quantifiable & concentr & tionף & 0.9 & -3.7 & 10 & & 0.078 & -0.31 & 0.076 & -0.30 & $1-$ & 4.1 & 0.12 & 0.46 & 0.096 & -0.38 \\
\hline
\end{tabular}

[] Estimated concentration; this concentration was between the minimum detectable and minimum quantifiable concentrations.

* Area sample

$\dagger$ Ceiling

‡ Carcinogen: exposures to carcinogens should be kept as low as feasible.

$\S$ Inhalable/respirable fraction

IThese values varied slightly from sample to sample. 
Table C6. Full-shift personal air sample results for metals in the tin shop $\left(\mu \mathrm{g} / \mathrm{m}^{3}\right)$

\begin{tabular}{|c|c|c|c|c|c|c|c|c|c|c|c|c|c|c|}
\hline \multirow[t]{2}{*}{ Job title* } & \multicolumn{2}{|c|}{ Time (minutes) } & \multicolumn{2}{|c|}{ Aluminum } & \multicolumn{2}{|c|}{ Cadmium } & \multicolumn{2}{|c|}{ Chromium } & \multicolumn{2}{|c|}{ Cobalt } & \multicolumn{2}{|c|}{ Copper } & \multicolumn{2}{|c|}{ Iron oxide } \\
\hline & Day 1 & Day 2 & Day 1 & Day 2 & Day 1 & Day 2 & Day 1 & Day 2 & Day 1 & Day 2 & Day 1 & Day 2 & Day 1 & Day 2 \\
\hline Car repairman 1 & 342 & - & ND & - & ND & - & 0.51 & - & ND & - & {$[0.16]$} & - & 14 & - \\
\hline Oiler 1 & 244 & - & ND & - & ND & - & {$[0.23]$} & - & ND & - & {$[0.21]$} & - & 8.3 & - \\
\hline Sheet metal worker 1 & 417 & 228 & ND & ND & ND & ND & 0.35 & 0.86 & ND & ND & 1.3 & {$[0.15]$} & 37 & 33 \\
\hline Sheet metal worker 2 & 360 & - & ND & - & ND & - & 0.82 & - & ND & - & {$[0.21]$} & - & 8.5 & - \\
\hline Sheet metal worker 3 & - & 320 & - & 17 & - & 0.33 & - & 17 & - & 0.3 & - & 2.1 & - & 1,600 \\
\hline Sheet metal worker 4 & - & 333 & - & ND & - & ND & - & 1.1 & - & ND & - & {$[0.29]$} & - & 29 \\
\hline \multicolumn{3}{|l|}{ OSHA PEL } & \multicolumn{2}{|c|}{$15,000 / 5,000 \dagger$} & \multicolumn{2}{|c|}{5} & \multicolumn{2}{|c|}{1,000} & \multicolumn{2}{|c|}{100} & \multicolumn{2}{|c|}{1,000} & \multicolumn{2}{|c|}{10,000} \\
\hline \multicolumn{3}{|l|}{ NIOSH REL } & \multicolumn{2}{|c|}{$10,000 / 5,000 \dagger$} & \multicolumn{2}{|c|}{ Cał } & \multicolumn{2}{|c|}{500} & \multicolumn{2}{|c|}{50} & \multicolumn{2}{|c|}{1,000} & \multicolumn{2}{|c|}{5,000} \\
\hline \multicolumn{3}{|l|}{ ACGIH TLV } & \multicolumn{2}{|c|}{$1,000 \S$} & \multicolumn{2}{|c|}{$10 / 2^{*}$} & \multicolumn{2}{|c|}{500} & \multicolumn{2}{|c|}{20} & \multicolumn{2}{|c|}{1,000} & \multicolumn{2}{|c|}{$5,000 \S$} \\
\hline \multicolumn{3}{|c|}{ Minimum detectable concentration $\uparrow$} & \multicolumn{2}{|c|}{$0.8-3$} & \multicolumn{2}{|c|}{$0.04-0.1$} & \multicolumn{2}{|c|}{$0.08-0.3$} & \multicolumn{2}{|c|}{$0.06-0.2$} & \multicolumn{2}{|c|}{$0.07-0.3$} & & \\
\hline Minimum quantifiable & entrationף & & 2.6 & & 0.11 & 0.44 & 0.2 & 1.1 & 0.21 & 0.85 & 0.25 & 0.99 & & 6.2 \\
\hline
\end{tabular}

[ ] Estimated concentration; this concentration was between the minimum detectable and minimum quantifiable concentrations.

* Data from one car repairman and four sheet metal workers are not presented because the data was uninterpretable.

$\dagger$ Total/respirable fraction

‡ Carcinogen: exposures to carcinogens should be kept as low as feasible.

$\S$ Respirable fraction

I These values varied slightly from sample to sample. 
Table C6 (continued). Full-shift personal air sample results for metals in the tin shop $\left(\mu \mathrm{g} / \mathrm{m}^{3}\right)$

\begin{tabular}{|c|c|c|c|c|c|c|c|c|c|c|c|c|c|c|c|c|}
\hline \multirow[t]{2}{*}{ Job title* } & \multicolumn{2}{|c|}{$\begin{array}{c}\text { Time } \\
\text { (minutes) }\end{array}$} & \multicolumn{2}{|c|}{ Lead } & \multicolumn{2}{|c|}{$\begin{array}{l}\text { Magnesium } \\
\text { oxide }\end{array}$} & \multicolumn{2}{|c|}{ Manganese } & \multicolumn{2}{|c|}{ Nickel } & \multicolumn{2}{|c|}{ Tin } & \multicolumn{2}{|c|}{$\begin{array}{l}\text { Titanium } \\
\text { dioxide }\end{array}$} & \multicolumn{2}{|c|}{ Zinc oxide } \\
\hline & Day 1 & Day 2 & Day 1 & Day 2 & Day 1 & Day 2 & Day 1 & Day 2 & Day 1 & Day 2 & Day 1 & Day 2 & Day 1 & Day 2 & Day 1 & Day 2 \\
\hline Car repairman 1 & 342 & - & ND & - & ND & - & 0.28 & - & 0.24 & - & ND & - & ND & - & 1.5 & - \\
\hline Oiler 1 & 244 & - & ND & - & ND & - & 0.39 & - & {$[0.04]$} & - & ND & - & ND & - & 0.83 & - \\
\hline Sheet metal worker 1 & 417 & 228 & {$[0.29]$} & ND & ND & ND & 3 & 0.55 & 0.13 & 0.49 & {$[0.75]$} & ND & {$[0.06]$} & ND & 5.9 & 0.27 \\
\hline Sheet metal worker 2 & 360 & - & {$[0.31]$} & - & ND & - & 0.27 & - & 0.39 & - & {$[0.52]$} & - & {$[0.05]$} & - & 0.52 & - \\
\hline Sheet metal worker 3 & - & 320 & - & {$[0.55]$} & - & ND & - & 10 & - & 9 & - & ND & - & 0.74 & - & 1.7 \\
\hline Sheet metal worker 4 & 一 & 333 & - & ND & 一 & ND & - & 0.39 & 一 & 0.63 & - & ND & 一 & ND & - & 0.23 \\
\hline \multicolumn{3}{|l|}{ OSHA PEL } & \multicolumn{2}{|c|}{50} & \multicolumn{2}{|c|}{15,000} & \multicolumn{2}{|c|}{$5,000 \dagger$} & \multicolumn{2}{|c|}{1,000} & \multicolumn{2}{|c|}{2,000} & \multicolumn{2}{|c|}{15,000} & \multicolumn{2}{|c|}{5,000} \\
\hline NIOSH REL & & & \multicolumn{2}{|c|}{50} & \multicolumn{2}{|c|}{ - } & \multicolumn{2}{|c|}{1,000} & \multicolumn{2}{|c|}{15} & \multicolumn{2}{|c|}{2,000} & \multicolumn{2}{|c|}{ Cał } & \multicolumn{2}{|c|}{5,000} \\
\hline ACGIH TLV & & & \multicolumn{2}{|c|}{50} & \multicolumn{2}{|c|}{10,000} & \multicolumn{2}{|c|}{$100 / 20 \S$} & \multicolumn{2}{|c|}{1,500} & \multicolumn{2}{|c|}{2,000} & \multicolumn{2}{|c|}{10,000} & \multicolumn{2}{|c|}{2,000} \\
\hline \multicolumn{3}{|c|}{ Minimum detectable concentration } & \multicolumn{2}{|c|}{$0.2-0.9$} & \multicolumn{2}{|c|}{$4-10$} & 0.02 & 0.09 & 0.02 & 0.09 & & & 0.0 & -0.1 & 0.02 & 0.09 \\
\hline Minimum quantifiable & oncentr & tionף & 0.9 & -3.7 & 10 & & 0.07 & -0.31 & 0.076 & -0.30 & $1-$ & & 0.12 & -0.46 & 0.09 & -0.38 \\
\hline
\end{tabular}

[ ] Estimated concentration; this concentration was between the minimum detectable and minimum quantifiable concentrations.

* Data from one car repairman and four sheet metal workers are not presented because the data was uninterpretable.

$\dagger$ Ceiling

‡ Carcinogen: exposures to carcinogens should be kept as low as feasible.

$\S$ Inhalable/respirable fraction

I These values varied slightly from sample to sample. 
Table C7. Short-term (29 minutes) personal air sample results for metals in the car shop while moving a train three times $\left(\mathrm{ug} / \mathrm{m}^{3}\right)^{\star}$

\begin{tabular}{lcccc}
\hline Metal & Day 1 & \multicolumn{3}{c}{ Exceeds OEL? } \\
\cline { 3 - 5 } & & OSHA & NIOSH & ACGIH \\
\hline Aluminum & ND & no & no & no \\
Cadmium & ND & no & no & no \\
Chromium & {$[1.3]$} & no & no & no \\
Cobalt & ND & no & no & no \\
Copper & 16 & no & no & no \\
Iron oxide & 330 & no & no & no \\
Lead & ND & no & no & no \\
Magnesium oxide & ND & no & no & no \\
Manganese & 2.6 & no & no & no \\
Nickel & {$[1.1]$} & no & no & no \\
Tin & ND & no & no & no \\
Titanium dioxide & {$[0.96]$} & no & no & no \\
Zinc oxide & 3.9 & no & no & no \\
\hline
\end{tabular}

[] Estimated concentration; this concentration was between the minimum detectable and minimum quantifiable concentrations.

* The minimum detectable concentrations $\left(\mu \mathrm{g} / \mathrm{m}^{3}\right)$ were 10 for aluminum, 0.5 for cadmium, 0.9 for cobalt, 4 for lead, 50 for magnesium oxide, and 5 for tin. The minimum quantifiable concentrations $\left(\mu \mathrm{g} / \mathrm{m}^{3}\right)$ were 4 for chromium, 1.1 for nickel, and 1.7 for titanium dioxide.

$\dagger$ Manganese and zinc oxide have STELs. The remaining analytes were compared to the 8-hr exposure limits and assumed that the employee was exposed to these concentrations for an entire shift. 
Table C8. Area noise measurements in the six support shops

\begin{tabular}{lccc}
\hline Shop & Noise measurement (dBA) & Task or location & $\begin{array}{c}\text { Distance from } \\
\text { task/location (feet) }\end{array}$ \\
\hline Electronics & $72-82$ & Under HVAC unit & 1 \\
Truck & $63-78$ & Workstations adjacent to HVAC unit & $1-3$ \\
& $93-96$ & Basement wheel \\
& $84-85$ & lathe operator station & $1-3$ \\
& $88-93$ & Pressure washing bay & 10 \\
Motor & $74-95$ & Impact wrench & 10 \\
Tin & $83-85$ & Impact wrench & 10 \\
& $85-102$ & Grinding metal & 5 \\
Contactor & $66-72$ & Cutting metal & 5 \\
Wheel & $74-76$ & Various workstations & $1-3$ \\
\hline
\end{tabular}




\begin{tabular}{|c|c|}
\hline Characteristic & Number of employees (\%) \\
\hline Male & $123(98)$ \\
\hline \multicolumn{2}{|l|}{ Age $(n=125)$} \\
\hline Median years (range) & $49(32-70)$ \\
\hline \multicolumn{2}{|l|}{ Length of employment at facility } \\
\hline Median years (range) & $12(1-26)$ \\
\hline \multicolumn{2}{|l|}{ Hours per week worked } \\
\hline Median hours (range) & $50(12-80)$ \\
\hline \multicolumn{2}{|l|}{ Race } \\
\hline Asian & $7(6)$ \\
\hline African American & $19(15)$ \\
\hline White & $85(67)$ \\
\hline American Indian/Alaska Native & $1(1)$ \\
\hline Multiple & $2(2)$ \\
\hline Other & $11(9)$ \\
\hline Hispanic $(n=124)$ & $10(8)$ \\
\hline \multicolumn{2}{|l|}{ Job title } \\
\hline Car repairman & $18(15)$ \\
\hline Electrician & $63(50)$ \\
\hline Gang foreman & $4(3)$ \\
\hline Machinist & $29(23)$ \\
\hline Oiler & $4(3)$ \\
\hline Other & $8(6)$ \\
\hline \multicolumn{2}{|l|}{ Department $(n=125)$} \\
\hline Contact & $16(13)$ \\
\hline Electronics & $24(19)$ \\
\hline Motor & $23(18)$ \\
\hline Tin & $14(11)$ \\
\hline Truck & $26(21)$ \\
\hline Wheel & $21(17)$ \\
\hline Other & $1(1)$ \\
\hline
\end{tabular}




\begin{tabular}{|c|c|}
\hline Health outcome & Number of employees (\%) \\
\hline Regular cough & $26(21)$ \\
\hline Sinus problems* & $69(55)$ \\
\hline Nasal symptoms* ${ }^{\star}$ & $79(63)$ \\
\hline Eye symptoms* $\ddagger$ & $61(48)$ \\
\hline Trouble breathing* $(n=125)$ & $34(27)$ \\
\hline Hearing problems§ & $37(29)$ \\
\hline \multicolumn{2}{|l|}{ Medical diagnoses } \\
\hline Recurrent sinusitis & $25(20)$ \\
\hline $\begin{array}{l}\text { Recurrent upper respiratory } \\
\text { infections }\end{array}$ & $20(16)$ \\
\hline Hearing loss & $30(24)$ \\
\hline Cancer & $4(3)$ \\
\hline
\end{tabular}

* Experienced in the last 12 months, excluding cold and flu

† Stuffy, itchy, or runny nose

¥ Watery or itchy eyes

$\S$ Ringing, roaring, or buzzing in ears for 5 minutes or more a day 


\section{Section D: Occupational Exposure Limits}

NIOSH investigators refer to mandatory (legally enforceable) and recommended OELs for chemical, physical, and biological agents when evaluating workplace hazards. OELs have been developed by federal agencies and safety and health organizations to prevent adverse health effects from workplace exposures. Generally, OELs suggest levels of exposure that most employees may be exposed to for up to 10 hours per day, 40 hours per week, for a working lifetime, without experiencing adverse health effects.

However, not all employees will be protected if their exposures are maintained below these levels. Some may have adverse health effects because of individual susceptibility, a preexisting medical condition, or a hypersensitivity (allergy). In addition, some hazardous substances act in combination with other exposures, with the general environment, or with medications or personal habits of the employee to produce adverse health effects. Most OELs address airborne exposures, but some substances can be absorbed directly through the skin and mucous membranes.

Most OELs are expressed as a time-weighted average (TWA) exposure. A TWA refers to the average exposure during a normal 8- to 10-hour workday. Some chemical substances and physical agents have recommended STEL or ceiling values. Unless otherwise noted, the STEL is a 15-minute TWA exposure. It should not be exceeded at any time during a workday. The ceiling limit should not be exceeded at any time.

In the United States, OELs have been established by federal agencies, professional organizations, state and local governments, and other entities. Some OELs are legally enforceable limits; others are recommendations.

- OSHA, an agency of the U.S. Department of Labor, publishes permissible exposure limits [29 CFR 1910 for general industry; 29 CFR 1926 for construction industry; and 29 CFR 1917 for maritime industry] called PELs. These legal limits are enforceable in workplaces covered under the Occupational Safety and Health Act of 1970.

- NIOSH RELs are recommendations based on a critical review of the scientific and technical information and the adequacy of methods to identify and control the hazard. NIOSH RELs are published in the NIOSH Pocket Guide to Chemical Hazards [NIOSH 2007]. NIOSH also recommends risk management practices (e.g., engineering controls, safe work practices, employee education/training, PPE, and exposure and medical monitoring) to minimize the risk of exposure and adverse health effects.

- Another set of OELs commonly used and cited in the United States include the threshold limit values or TLVs, which are recommended by the ACGIH. The ACGIH TLVs are developed by committee members of this professional organization from a review of the published, peer-reviewed literature. TLVs are not consensus standards. They are considered voluntary exposure guidelines for use by industrial hygienists and others trained in this discipline "to assist in the control of health hazards" [ACGIH 2021].

D-1 
Outside the United States, OELs have been established by various agencies and organizations and include legal and recommended limits. The Institut für Arbeitsschutz der Deutschen Gesetzlichen Unfallversicherung (Institute for Occupational Safety and Health of the German Social Accident Insurance) maintains a database of international OELs from European Union member states, Canada (Québec), Japan, Switzerland, and the United States. The database, available at https://www.dguv.de/ifa/gestis/gestis-stoffdatenbank/index-2.jsp, contains international limits for more than 2,000 hazardous substances and is updated periodically.

OSHA (Public Law 91-596) requires an employer to furnish employees a place of employment free from recognized hazards that cause or are likely to cause death or serious physical harm. This is true in the absence of a specific OEL. It also is important to keep in mind that OELs may not reflect current health-based information.

When multiple OELs exist for a substance or agent, NIOSH investigators generally encourage employers to use the lowest OEL when making risk assessment and risk management decisions.

\section{Noise}

Noise-induced hearing loss (NIHL) is an irreversible condition that progresses with noise exposure. It is caused by damage to the nerve cells of the inner ear and, unlike some other types of hearing disorders, cannot be treated medically [Berger et al. 2003]. More than 22 million U.S. employees are estimated to be exposed to workplace noise levels above $85 \mathrm{dBA}$ [Tak et al. 2009]. NIOSH estimates that employees exposed to an average daily noise level of $85 \mathrm{dBA}$ over a 40 -year working lifetime have an $8 \%$ excess risk of material hearing impairment. This excess risk increases to $25 \%$ for an average daily noise exposure of $90 \mathrm{dBA}$ [NIOSH 1998]. NIOSH defines material hearing impairment as an average of the hearing threshold levels for both ears that exceeds $25 \mathrm{~dB}$ at frequencies of 1,000 $\mathrm{Hertz}(\mathrm{Hz}), 2,000 \mathrm{~Hz}$, 3,000 Hz, and 4,000 Hz.

Although hearing ability commonly declines with age, exposure to excessive noise can increase the rate of hearing loss. In most cases, NIHL develops slowly from repeated exposure to noise over time, but the progression of hearing loss is typically the greatest during the first several years of noise exposure. NIHL can also result from short-duration exposures to high noise levels or even from a single exposure to an impulse noise or a continuous noise, depending on the intensity of the noise and the individual's susceptibility to NIHL [Berger et al. 2003]. Noise-exposed employees can develop substantial NIHL before it is clearly recognized. Even mild hearing losses can impair a person's ability to understand speech and hear many important sounds. In addition, some people with NIHL also develop tinnitus. Tinnitus is a condition in which a person perceives sound in one or both ears, but no external sound is present. Persons with tinnitus often describe hearing ringing, hissing, buzzing, whistling, clicking, or chirping like crickets. Tinnitus can be intermittent or continuous and the perceived volume can range from soft to loud. Currently, there is no cure for tinnitus.

The preferred unit for reporting of noise measurements is the dBA. A-weighting is used because it approximates the "equal loudness perception characteristics of human hearing for pure tones relative to a reference of $40 \mathrm{~dB}$ at a frequency of $1,000 \mathrm{~Hz}$ ” and is considered to provide a better estimation of hearing loss risk than using unweighted or other weighting measurements [Berger et al. 2003]. 
Employees exposed to noise should have baseline and yearly hearing tests to evaluate their hearing thresholds and determine whether their hearing has changed over time. Hearing testing should be done in a quiet location, such as an audiometric test booth where background noise does not interfere with accurate measurement of hearing thresholds. In workplace hearing conservation programs, hearing thresholds must be measured at $500 \mathrm{~Hz}, 1,000 \mathrm{~Hz}, 2,000 \mathrm{~Hz}, 3,000 \mathrm{~Hz}, 4,000 \mathrm{~Hz}$, and 6,000 Hz. Additionally, NIOSH recommends testing at 8,000 $\mathrm{Hz}$ [NIOSH 1998]. The OSHA hearing conservation standard requires analysis of changes from baseline hearing thresholds to determine if the changes are substantial enough to meet OSHA criteria for a standard threshold shift. OSHA defines a standard threshold shift as a change in hearing threshold (relative to the baseline hearing test) of an average of $10 \mathrm{~dB}$ or more at 2,000 Hz, 3,000 Hz, and 4,000 Hz in either ear [29 CFR 1910.95]. If a standard threshold shift occurs, the company must determine if the hearing loss also meets the requirements to be recorded on the OSHA Form 300 Log of Work-Related Injuries and Illnesses [29 CFR 1904.1]. In contrast to OSHA, NIOSH defines a significant threshold shift as a change in the hearing threshold level of $15 \mathrm{~dB}$ or more (relative to the baseline hearing test) at any test frequency in either ear measured twice in succession [NIOSH 1998].

NIOSH has a REL for noise of $85 \mathrm{dBA}$, as an 8-hour TWA. For calculating exposure limits, NIOSH uses a 3-dB time/intensity trading relationship, or exchange rate. Using the NIOSH criterion, an employee can be exposed to $88 \mathrm{dBA}$ for no more than 4 hours, $91 \mathrm{dBA}$ for 2 hours, $94 \mathrm{dBA}$ for 1 hour, $97 \mathrm{dBA}$ for 0.5 hours, etc. Exposure to impulsive noise should never exceed $140 \mathrm{dBA}$. For extended work shifts NIOSH adjusts the REL to $84.5 \mathrm{dBA}$ for a 9-hour shift, $84.0 \mathrm{dBA}$ for a 10-hour shift, 83.6 dBA for an 11-hour shift, and 83.2 dBA for a 12-hour work shift. NIOSH recommends the use of hearing protection and implementation of a hearing loss prevention program when noise exposures exceed the REL [NIOSH 1998].

The OSHA noise standard specifies a PEL of $90 \mathrm{dBA}$ and an AL of $85 \mathrm{dBA}$, both as 8-hour TWAs. OSHA uses a less conservative 5-dB exchange rate for calculating the PEL and AL. Using the OSHA criterion, an employee may be exposed to noise levels of $95 \mathrm{dBA}$ for no more than 4 hours, $100 \mathrm{dBA}$ for 2 hours, $105 \mathrm{dBA}$ for 1 hour, $110 \mathrm{dBA}$ for 0.5 hours, etc. Exposure to impulsive or impact noise must not exceed $140 \mathrm{~dB}$ peak noise level. OSHA does not adjust the PEL for extended work shifts. However, the $\mathrm{AL}$ is adjusted to $84.1 \mathrm{dBA}$ for a 9-hour shift, $83.4 \mathrm{dBA}$ for a 10-hour shift, $82.7 \mathrm{dBA}$ for an 11-hour shift, and $82.1 \mathrm{dBA}$ for a 12-hour work shift. OSHA requires implementation of a hearing conservation program when noise exposures exceed the AL [29 CFR 1910.95].

\section{Lead}

Inorganic lead is a naturally occurring, soft metal that has been mined and used in industry since ancient times. It comes in many forms (e.g., lead acetate, lead chloride, lead chromate, lead nitrate, lead oxide, lead phosphate, and lead sulfate). Lead is considered toxic to all organ systems and serves no useful purpose in the body.

Occupational exposure to inorganic lead occurs via inhalation of lead-containing dust and fume and ingestion of lead particles from contact with lead-contaminated surfaces. Exposure may also occur through transfer of lead to the mouth from contaminated hands or cigarettes when careful attention to hygiene, particularly handwashing, is not practiced. In addition to the inhalation and ingestion routes of 
exposure, lead can be absorbed through the skin, particularly through damaged skin [Filon et al. 2006; Stauber et al. 1994; Sun et al. 2002].

Workplace settings with exposure to lead and lead compounds include smelting and refining, scrap metal recovery, automobile radiator repair, construction, and demolition (including abrasive blasting), and firing ranges. Occupational exposures also occur among workers who apply or remove lead-based paint and among welders who burn or torch-cut metal structures.

\section{Blood Lead Levels}

In most cases, an individual's BLL is a good indication of recent exposure to lead because the half-life of lead (the time interval it takes for the quantity in the body to be reduced by half its initial value) is 1-2 months [CDC 2013b; Lauwerys and Hoet 2001; Moline and Landrigan 2005]. Most lead in the body is stored in the bones, with a half-life of years to decades. Measuring bone lead, however, is primarily done only for research. Elevated zinc protoporphyrin levels have also been used as an indicator of chronic lead intoxication. Because other factors, such as iron deficiency, can cause an elevated zinc protoporphyrin level, monitoring the BLL over time is more specific for evaluating chronic occupational lead exposure.

BLLs in adults in the United States have declined consistently over time. The average geometric mean BLL of all adults in 2009-2010 was $1.2 \mu \mathrm{g} / \mathrm{dL}$ [CDC 2018]. The NIOSH ABLES program uses a surveillance case definition for an elevated BLL in adults of $5 \mu \mathrm{g} / \mathrm{dL}$ of blood or higher [CDC 2018]. Very high BLLs are defined as BLLs $\geq 40 \mu \mathrm{g} / \mathrm{dL}$. From 2002-2011, occupational exposures accounted for $91 \%$ of adults with very high BLLs (where exposure source was known) [CDC 2013b]. This underscores the need to increase efforts to prevent lead exposures in the workplace.

\section{Occupational Exposure Limits}

In the United States, employers in general industry are required by law to follow the OSHA lead standard [29 CFR1910.1025]. This standard was established in 1978 and has not yet been updated to reflect the current scientific knowledge regarding the health effects of lead exposure [OSHA 1978]. Under this standard, the PEL for airborne exposure to lead is 50 micrograms per cubic meter of air $\left(\mu \mathrm{g} / \mathrm{m}^{3}\right)$ of air for an 8-hour TWA. The standard requires lowering the PEL for shifts that exceed 8 hours, medical monitoring for employees exposed to airborne lead at or above the OSHA AL of $30 \mu \mathrm{g} / \mathrm{m}^{3}$ (8-hour TWA), medical removal of employees whose average BLL is $50 \mu \mathrm{g} / \mathrm{dL}$ or greater, and economic protection for medically removed workers. Medically removed workers cannot return to jobs involving lead exposure until their BLL is below $40 \mu \mathrm{g} / \mathrm{dL}$.

In the United States, other guidelines for lead exposure, which are not legally enforceable, are often followed. Similar to the OSHA lead standard, these guidelines were set years ago and have not yet been updated to reflect current scientific knowledge. NIOSH has a recommended exposure limit (REL) for lead of $50 \mu \mathrm{g} / \mathrm{m}^{3}$ averaged over an 8-hour work shift [NIOSH 2007]. The ACGIH TLV for lead of $50 \mu \mathrm{g} / \mathrm{m}^{3}$ (8-hour TWA), with worker BLLs to be controlled to, or below, $30 \mu \mathrm{g} / \mathrm{dL}$. The ACGIH designates lead as an animal carcinogen [ACGIH 2021]. In 2013, the California Department of Public Health $(\mathrm{CDPH})$ recommended that Cal/OSHA lower the PEL for lead to 0.5 to $2.1 \mu \mathrm{g} / \mathrm{m}^{3}$ (8-hour TWA) to keep BLLs below the range of 5 to $10 \mu \mathrm{g} / \mathrm{dL}$ [Billingsley 2013].

\section{D-4}


Neither NIOSH nor OSHA has established surface contamination limits for lead in the workplace. The U.S. Environmental Protection Agency and the U.S. Department of Housing and Urban Development limit lead on surfaces in public buildings and child-occupied housing to less than 40 micrograms of lead per square foot [EPA 1998; HUD 2012]. OSHA requires in its substance-specific standard for lead that all surfaces be maintained as free as practicable of accumulations of lead [29 CFR 1910.1025(h)(1)]. An employer with workplace exposures to lead must implement regular and effective cleaning of surfaces in areas such as change areas, storage facilities, and lunchroom/eating areas to ensure they are as free as practicable from lead contamination.

\section{Health Effects}

The PEL, REL, and TLV may prevent overt symptoms of lead poisoning, but do not protect workers from lead's contributions to conditions such as hypertension, renal dysfunction, reproductive, and cognitive effects [Brown-Williams et al. 2009; Institute of Medicine 2012; Schwartz and Hu 2007;

Schwartz and Stewart 2007]. Generally, acute lead poisoning with symptoms has been documented in persons having BLLs above $70 \mu \mathrm{g} / \mathrm{dL}$. These BLLs are rare today in the United States, largely as a result of workplace controls put in place to comply with current OELs. When present, acute lead poisoning can cause myriad adverse health effects including abdominal pain, hemolytic anemia, and neuropathy. Lead poisoning has, in very rare cases, progressed to encephalopathy and coma [Moline and Landrigan 2005].

People with chronic lead poisoning, which is more likely at current occupational exposure levels, may not have symptoms or they may have nonspecific symptoms that may not be recognized as being associated with lead exposure. These symptoms include headache, joint and muscle aches, weakness, fatigue, irritability, depression, constipation, anorexia, and abdominal discomfort [Moline and Landrigan 2005].

The National Toxicology Program (NTP) recently released a monograph on the health effects of low-level lead exposure [NTP 2012]. For adults, the NTP concluded the following about the evidence regarding health effects of lead (Table D1). 
Table D1. Evidence regarding health effects of lead in adults

\begin{tabular}{|c|c|c|c|}
\hline Health area & $\begin{array}{c}\text { NTP } \\
\text { conclusion }\end{array}$ & Principal health effects & $\begin{array}{l}\text { Blood lead } \\
\text { evidence }\end{array}$ \\
\hline \multirow[t]{3}{*}{ Neurological } & Sufficient & Increased incidence of essential tremor & $Y e s,<10 \mu \mathrm{g} / \mathrm{dL}$ \\
\hline & Limited & $\begin{array}{l}\text { Psychiatric effects, decreased hearing, } \\
\text { decreased cognitive function, increased } \\
\text { incidence of amyotrophic lateral sclerosis }\end{array}$ & Yes, $<10 \mu \mathrm{g} / \mathrm{dL}$ \\
\hline & Limited & Increased incidence of essential tremor & Yes, $<5 \mu \mathrm{g} / \mathrm{dL}$ \\
\hline Immune & Inadequate & & Unclear \\
\hline \multirow[t]{2}{*}{ Cardiovascular } & Sufficient & $\begin{array}{l}\text { Increased blood pressure and } \\
\text { increased risk of hypertension }\end{array}$ & Yes, $<10 \mu \mathrm{g} / \mathrm{dL}$ \\
\hline & Limited & $\begin{array}{l}\text { Increased cardiovascular-related mortality } \\
\text { and electrocardiography abnormalities }\end{array}$ & Yes, $<10 \mu \mathrm{g} / \mathrm{dL}$ \\
\hline Renal & Sufficient & Decreased glomerular filtration rate & Yes, $<5 \mu \mathrm{g} / \mathrm{dL}$ \\
\hline \multirow[t]{6}{*}{ Reproductive } & Sufficient & Women: reduced fetal growth & Yes, $<5 \mu \mathrm{g} / \mathrm{dL}$ \\
\hline & Sufficient & $\begin{array}{l}\text { Men: adverse changes in sperm parameters } \\
\text { and increased time to pregnancy }\end{array}$ & Yes, $\geq 15-20 \mu \mathrm{g} / \mathrm{dL}$ \\
\hline & Limited & $\begin{array}{l}\text { Women: increase in spontaneous abortion } \\
\text { and preterm birth }\end{array}$ & Yes, $<10 \mu \mathrm{g} / \mathrm{dL}$ \\
\hline & Limited & Men: decreased fertility & Yes, $\geq 10 \mu \mathrm{g} / \mathrm{dL}$ \\
\hline & Limited & Men: spontaneous abortion & Yes, $\geq 31 \mu \mathrm{g} / \mathrm{dL}$ \\
\hline & Inadequate & $\begin{array}{l}\text { Women and Men: stillbirth, } \\
\text { endocrine effects, birth defects }\end{array}$ & Unclear \\
\hline
\end{tabular}

Various organizations have assessed the relationship between lead exposure and cancer. According to the Agency for Toxic Substances and Disease Registry [ATSDR 2007] and the NTP [NTP 2011], inorganic lead compounds are reasonably anticipated to cause cancer in humans. The International Agency for Research on Cancer classifies inorganic lead as probably carcinogenic to humans [IARC 2006].

\section{Medical Management}

To prevent acute and chronic health effects, a panel of experts convened by the Association of Occupational and Environmental Clinics published guidelines for the management of adult lead exposure [Kosnett et al. 2007]. The panel recommended BLL testing for all lead-exposed employees, regardless of the airborne lead concentration. These recommendations do not apply to pregnant women, who should avoid BLLs $\geq 5 \mu \mathrm{g} / \mathrm{dL}$. Removal from lead exposure should be considered if control measures over an extended period do not decrease BLLs to $<10 \mu \mathrm{g} / \mathrm{dL}$ or an employee has a medical condition that would increase the risk of adverse health effects from lead exposure. These guidelines were endorsed by CSTE and CDPH in 2009 and the American College of Occupational and Environmental Medicine (ACOEM) in 2010 [ACOEM 2010; CDPH 2009; CSTE 2009]. CSTE published updated guidelines in 2013 to reflect the new definition of an elevated BLL in adults of $5 \mu \mathrm{g} / \mathrm{dL}$ [CSTE 2013]. CDPH recommends keeping BLLs below 5 to $10 \mu \mathrm{g} / \mathrm{dL}$ in 2013 [Billingsley 2013] and updated their medical management guidelines in 2014 [CDPH 2014]. In 2015, NIOSH designated $5 \mu \mathrm{g} / \mathrm{dL}$ of whole blood, in a venous blood sample, as the reference BLL for adults. An 
elevated BLL is defined as a BLL $\geq 5 \mu \mathrm{g} / \mathrm{dL}$. Table D2 incorporates recommendations from the expert panel guidelines and those from CDPH and CSTE.

Table D2. Health-based medical surveillance recommendations for lead-exposed employees

\begin{tabular}{|c|c|}
\hline Category of exposure & Recommendations \\
\hline All lead exposed workers & $\begin{array}{l}\text { - Baseline or preplacement medical history and physical examination, } \\
\text { baseline BLL, and serum creatinine }\end{array}$ \\
\hline $\mathrm{BLL}<5 \mu \mathrm{g} / \mathrm{dL}$ & $\begin{array}{l}\text { - BLL monthly for first } 3 \text { months placement, or upon change in task to higher } \\
\text { exposure, then BLL every } 6 \text { months; if } B L L \text { increases } \geq 5 \mu \mathrm{g} / \mathrm{dL} \text {, evaluate } \\
\text { exposure and protective measures, and increase monitoring if indicated }\end{array}$ \\
\hline BLL 5-9 $\mu \mathrm{g} / \mathrm{dL}$ & $\begin{array}{l}\text { - Discuss health risks } \\
\text { - Minimize exposure } \\
\text { - Consider removal for pregnancy and certain medical conditions } \\
\text { - } \text { BLL monthly for first } 3 \text { months placement or every } 2 \text { months for the first } \\
6 \text { months placement, or upon change in task to higher exposure, then } \\
\text { BLL every } 6 \text { months; if BLL increases } \geq 5 \mu \mathrm{g} / \mathrm{dL} \text {, evaluate exposure and } \\
\text { protective measures, and increase monitoring if indicated }\end{array}$ \\
\hline BLL $10-19 \mu \mathrm{g} / \mathrm{dL}$ & $\begin{array}{l}\text { - Discuss health risks } \\
\text { - } \text { Decrease exposure } \\
\text { - } \text { Remove from exposure for pregnancy } \\
\text { - } \text { Consider removal for certain medical conditions or BLL } \geq 10 \mu \mathrm{g} / \mathrm{dL} \text { for } \\
\text { - } \text { extended period } \\
\text { BLL every } 3 \text { months; evaluate exposure, engineering controls, and } \\
\text { - } \text { work practices; consider removal. } \\
\text { Revert to BLL every } 6 \text { months after } 3 \mathrm{BLLs}<10 \mu \mathrm{g} / \mathrm{dL}\end{array}$ \\
\hline BLL 20-29 $\mu \mathrm{g} / \mathrm{dL}$ & $\begin{array}{l}\text { - Remove from exposure for pregnancy } \\
\text { - Remove from exposure if repeat BLL measured in } 4 \text { weeks remains } \\
\geq 20 \mu \mathrm{g} / \mathrm{dL} \\
\text { - } \\
\text { - } \text { Mnnual lead medical exam recommended } \\
\text { - Consider return to work after } 2 \mathrm{BLLs}<15 \mu \mathrm{g} / \mathrm{dL} \text { a month apart, } \\
\text { then monitor as above }\end{array}$ \\
\hline BLL 30-49 $\mu \mathrm{g} / \mathrm{dL}$ & $\begin{array}{l}\text { - } \text { Remove from exposure } \\
\text { - } \text { Prompt medical evaluation } \\
\text { - } \text { Monthly BLL testing } \\
\text { - } \text { Consider return to work after } 2 \mathrm{BLLs}<15 \mu \mathrm{g} / \mathrm{dL} \text { a month apart, then } \\
\text { monitor as above }\end{array}$ \\
\hline BLL 50-79 $\mu \mathrm{g} / \mathrm{dL}$ & $\begin{array}{l}\text { - Remove from exposure } \\
\text { - Prompt medical evaluation } \\
\text { - Consider chelation with significant symptoms }\end{array}$ \\
\hline $\mathrm{BLL} \geq 80 \mu \mathrm{g} / \mathrm{dL}$ & $\begin{array}{l}\text { - Remove from exposure } \\
\text { - Urgent medical evaluation } \\
\text { - } \quad \text { Chelation may be indicated }\end{array}$ \\
\hline
\end{tabular}

Adapted from Kosnett et al. 2007, CSTE 2013, and CDPH 2014 


\section{Take-home Contamination}

Occupational exposures to lead can result in exposures to household members, including children, from take-home contamination. Take-home contamination occurs when lead dust is transferred from the workplace on employees' skin, clothing, shoes, and other personal items to their vehicle and home [CDC 2009, 2012]. The CDC considers a BLL in children of $5 \mu \mathrm{g} / \mathrm{dL}$ or higher as a reference level above which public health actions should be initiated, and states that no safe BLL in children has been identified [CDC 2013a].

The U.S. Congress passed the Workers' Family Protection Act in 1992 (29 U.S.C. 671a). The Act required NIOSH to study take-home contamination from workplace chemicals and substances, including lead. NIOSH found that take-home exposure is a widespread problem [NIOSH 1995]. Workplace measures effective in preventing take-home exposures were (1) reducing exposure in the workplace, (2) changing clothes before going home and leaving soiled clothing at work for laundering, (3) storing street clothes in areas separate from work clothes, (4) showering before leaving work, and (5) prohibiting removal of toxic substances or contaminated items from the workplace. NIOSH noted that preventing take-home exposure is critical because decontaminating homes and vehicles is not always effective. Normal house cleaning and laundry methods are inadequate, and decontamination can expose the people doing the cleaning and laundry. 


\section{Section E: References}

\section{Methods, Results, and Discussion}

Aldrich T, Sinks T [2002]. Things to know and do about cancer clusters. Cancer Invest 20(5-6):810816, https://doi.org/10.1081/CNV-120003546.

Asthma and Allergy Foundation of America [2020]. Rhinitis (nasal allergies). Arlington, VA: AAFA, https://www.aafa.org/rhinitis-nasal-allergy-hayfever/.

CDC [2012]. Cancer clusters. Atlanta, GA: U.S. Department of Health and Human Services, Centers for Disease Control and Prevention, http://www.cdc.gov/nceh/clusters/about.htm.

CDC [2016]. National Notifiable Diseases Surveillance System (NNDSS): lead, elevated blood levels 2016 case definition. Atlanta, GA: U.S. Department of Health and Human Services, Centers for Disease Control and Prevention, https://wwwn.cdc.gov/nndss/conditions/lead-elevated-blood-levels/casedefinition/2016/.

CDC [2018]. Adult blood lead epidemiology and surveillance. Adult Blood Lead Epidemiology and Surveillance (ABLES). Atlanta, GA: U.S. Department of Health and Human Services, Centers for Disease Control and Prevention, http://www.cdc.gov/niosh/topics/ables/description.html.

CSTE [2015]. Public health reporting and national notification for elevated blood lead levels. CSTE position statement 15-EH-01. Atlanta, GA: Council of State and Territorial Epidemiologists, https://c.ymcdn.com/sites/www.cste.org/resource/resmgr/2015PS/2015PSFinal/15-EH-01.pdf.

NHIS [2018]. Age-adjusted percentages (with standard errors) of selected respiratory diseases among adults aged 18 and over, by selected characteristics: United States, 2018. Atlanta, GA: U.S. Department of Health and Human Services, Centers for Disease Control and Prevention, National Health Information Survey, https://ftp.cdc.gov/pub/Health Statistics/NCHS/NHIS/SHS/2018 SHS Table A-2.pdf.

NIOSH [1998]. Criteria for a recommended standard: occupational noise exposure (revised criteria 1998). Cincinnati, OH: U.S. Department of Health and Human Services, Centers for Disease Control and Prevention, National Institute for Occupational Safety and Health, DHHS (NIOSH) Publication No. 98-126, http://www.cdc.gov/niosh/docs/98-126/pdfs/98-126.pdf.

NIOSH [2021]. NIOSH manual of analytical methods (NMAM). 5th ed. O’Connor PF, Ashley K, eds. Cincinnati, OH: U.S. Department of Health and Human Services, Centers for Disease Control and Prevention, National Institute for Occupational Safety and Health, DHHS (NIOSH) Publication No. 2014-151, http://www.cdc.gov/niosh/nmam.

OSHA [1998]. 1910.134 Respiratory Protection Standard: personal protective equipment. Washington, DC: U.S. Department of Labor, Occupational Health and Safety Administration, https://www.osha.gov/laws-regs/regulations/standardnumber/1910/1910.134.

OSHA [2012]. Hazard communication. Washington, DC: U.S. Department of Labor, Occupational Health and Safety Administration, https://www.osha.gov/dsg/hazcom/2012standard.html. 
Singh K, Axelrod S, Bielory L [2010]. The epidemiology of ocular and nasal allergy in the United States, 1988-1994. J Allergy Clin Immunol 126(4):778-783, https://doi.org/10.1016/j.jaci.2010.06.050.

Thun MJ, Sinks T [2004]. Understanding cancer clusters. CA Cancer J Clin 54(5):273-290, https://doi.org/10.3322/canjclin.54.5.273.

\section{Occupational Exposure Limits}

ACGIH [2021]. $2021 \mathrm{TLVs}^{\circledR}$ and BEIs ${ }^{\circledR}$ : threshold limit values for chemical substances and physical agents and biological exposure indices. Cincinnati, OH: American Conference of Governmental Industrial Hygienists.

ACOEM [2010]. ACOEM provides input to OSHA on key issues facing agency in 2010. Letter to David Michaels. Elk Grove Village, IL: American College of Occupational and Environmental Medicine, http:/ / beta.acoem.org/Page2Column.aspx?PageID=7392\&id=6676.

ATSDR [2007]. Toxicological profile for lead. Atlanta, GA: U.S. Department of Health and Human Services, Agency for Toxic Substances and Disease Registry, https://www.atsdr.cdc.gov/toxprofiles/tp.asp?id=96\&tid=22.

Berger EH, Royster LH, Royster JD, Driscoll DP, Layne M, eds. [2003]. The noise manual. 5th rev. ed. Fairfax, VA: American Industrial Hygiene Association, https://doi.org/10.3320/978-1-931504-02-7.

Billingsley KJ [2013]. Letter from KJ Billingsley, California Department of Public Health, to Juliann Sum, Division of Occupational Safety and Health (Cal/OSHA), California Department of Industrial Relations, September 30.

Brown-Williams H, Lichterman J, Kosnett M [2009]. Indecent exposure: lead puts workers and families at risk. Health Research for Action, University of California, Berkeley. Perspectives 4(1):1-9, http://www.healthresearchforaction.org/sites/default/files/PDF PERSPECTIVES IndecentExp $\% 20$ FNL 0.pdf.

CDC [2009]. Childhood lead poisoning associated with lead dust contamination of family vehicles and child safety seats-Maine, 2008. MMWR 58(32):890-893, https://www.cdc.gov/mmwr/preview/mmwrhtml/mm5832a2.htm.

CDC [2012]. Take-home lead exposure among children with relatives employed at a battery recycling facility_Puerto Rico, 2011. MMWR 61(47):967-970, https://www.cdc.gov/mmwr/preview/mmwrhtml/mm6147a4.htm?s cid=mm6147a4 w.

CDC [2013a]. Blood lead levels in children aged 1-5 years-United States, 1999-2010. MMWR 62(13):245-248, https://www.cdc.gov/mmwr/preview/mmwrhtml/mm6213a3.htm?s cid=mm6213a3 w.

CDC [2013b]. Very high blood lead levels among adults - United States, 2002-2011. MMWR 62(47):967-971, https://www.cdc.gov/mmwr/preview/mmwrhtml/mm6247a6.htm.

CDC [2016]. National Notifiable Diseases Surveillance System (NNDSS), lead, elevated blood levels 2016 case definition, https://wwwn.cdc.gov/nndss/conditions/lead-elevated-blood-levels/casedefinition/2016/. 
CDC [2018]. Adult blood lead epidemiology and surveillance. Adult Blood Lead Epidemiology and Surveillance (ABLES), http://www.cdc.gov/niosh/topics/ables/description.html.

CDPH [2009]. Medical guidelines for the lead-exposed worker. Sacramento, CA: California Department of Public Health, Occupational Lead Poisoning Prevention Program, https://www.cdph.ca.gov/Programs/CCDPHP/DEODC/OHB/OLPPP/CDPH $\% 20$ Document $\% 20$ Library/medgdln.pdf.

CDPH [2014]. Health-based guidelines for blood lead levels in adults. Sacramento, CA: California Department of Public Health, Occupational Lead Poisoning Prevention Program, https://www.cdph.ca.gov/Programs/CCDPHP/DEODC/OHB/OLPPP/CDPH $\% 20 D o c u m e n t \% 20$ Library/AdultMgtGuide.pdf.

CSTE [2009]. Public health reporting and national notification for elevated blood lead levels. CSTE position statement 09-OH-02. Atlanta, GA: Council of State and Territorial Epidemiologists, http://c.ymcdn.com/sites/www.cste.org/resource/resmgr/PS/09-OH-02.pdf.

CSTE [2013]. Management guidelines for blood lead levels in adults. Atlanta, GA: Council of State and Territorial Epidemiologists,

http://c.ymcdn.com/sites/www.cste.org/resource/resmgr/OccupationalHealth/ManagementGuidelin esforAdult.pdf.

CSTE [2015]. Public health reporting and national notification for elevated blood lead levels. CSTE position statement 15-EH-01. Atlanta, GA: Council of State and Territorial Epidemiologists, https://c.ymcdn.com/sites/www.cste.org/resource/resmgr/2015PS/2015PSFinal/15-EH-01.pdf.

EPA [1998]. Risk analysis to support standards for lead in paint, dust, and soil. Washington, DC: Environmental Protection Agency, EPA-747-R097-006, https://www.epa.gov/lead/risk-analysissupport-standards-lead-paint-dust-and-soil-volume-i-chapters-1-7-and-appendix-epa.

Filon FL, Boeniger M, Maina G, Adami G, Spinelli P, Damian A [2006]. Skin absorption of inorganic lead (PbO) and the effect of skin cleansers. J Occup Environ Med 48(7):692-699, https://doi.org/10.1097/01.jom.0000214474.61563.1c.

HUD [2012]. Guidelines for the evaluation and control of lead-based paint hazards in housing. Washington, DC: Housing and Urban Development, http://portal.hud.gov/hudportal/HUD?src=/program offices/healthy homes/lbp/hudguidelines.

IARC [2006]. IARC Monographs on the evaluation of carcinogenic risks to humans. Inorganic and organic lead compounds. Vol. 87. Lyon, France: World Health Organization, International Agency for Research on Cancer, https://monographs.iarc.fr/iarc-monographs-on-the-evaluation-of-carcinogenicrisks-to-humans-34/.

Institute of Medicine [2012]. Potential health risks from recurrent lead exposure of DOD firing range personnel. Washington, DC: National Academies Press, https://www.ncbi.nlm.nih.gov/books/NBK206966/pdf/Bookshelf NBK206966.pdf. 
Kosnett MJ, Wedeen RP, Rothenberg SJ, Hipkins KL, Materna BL, Schwartz BS, Hu H, Woolf A [2007]. Recommendations for medical management of adult blood lead exposure. Environ Health Perspect 115(3):463-471, https://doi.org/10.1289/ehp.9784.

Lauwerys RR, Hoet P [2001]. Industrial chemical exposure: guidelines for biological monitoring. 3rd ed. Boca Raton, FL: CRC Press, https://doi.org/10.1201/9781482293838.

Moline JM, Landrigan PJ [2005]. Lead. In: Rosenstock L, Cullen MR, Brodkin CA, Redlich CA, eds. Textbook of clinical occupational and environmental medicine. 2nd ed. Philadelphia, PA: Elsevier Saunders, https://doi.org/10.1016/B978-0-7216-8974-6.X5001-5.

NIOSH [1995]. Report to Congress on the workers' home contamination study conducted under the Workers' Family Protection Act (29 U.S.C. 671a). Cincinnati, OH: U.S. Department of Health and Human Services, Centers for Disease Control and Prevention, National Institute for Occupational Safety and Health, DHHS (NIOSH) Publication No. 95-123, http://www.cdc.gov/niosh/docs/95$123 /$.

NIOSH [1998]. Criteria for a recommended standard: occupational noise exposure (revised criteria 1998). Cincinnati, OH: U.S. Department of Health and Human Services, Centers for Disease Control and Prevention, National Institute for Occupational Safety and Health, DHHS (NIOSH) Publication No. 98-126, http://www.cdc.gov/niosh/docs/98-126/pdfs/98-126.pdf.

NTP [2011]. Report on carcinogens: lead and lead compounds. 14th ed. Research Triangle Park, NC: U.S. Department of Health and Human Services, National Institutes of Health, National Institute of Environmental Health Sciences, National Toxicology Program, http://ntp.niehs.nih.gov/ntp/roc/twelfth/profiles/Lead.pdf.

NTP [2012]. NTP Monograph: health effects of low-level lead. Research Triangle Park, NC: U.S. Department of Health and Human Services, National Institutes of Health, National Institute of Environmental Health Sciences, National Toxicology Program, https://ntp.niehs.nih.gov/ntp/ohat/lead/final/monographhealtheffectslowlevellead newissn 508.pdf.

OSHA [1978]. Lead 29 CFR 1910.1025. Washington, DC: U.S. Department of Labor, Occupational Safety and Health Administration, https://www.osha.gov/lawsregs/regulations/standardnumber/1910/1910.1025.

Schwartz BS, Hu H [2007]. Adult lead exposure: time for change. Environ Health Perspect 115(3):451454, https://doi.org/10.1289/ehp.9782.

Schwartz BS, Stewart WF [2007]. Lead and cognitive function in adults: a questions and answers approach to a review of the evidence for cause, treatment, and prevention. Int Rev Psychiatry 19(6):671-692, https://doi.org/10.1080/09540260701797936.

Stauber JL, Florence TM, Gulson B, Dale L [1994]. Percutaneous absorption of inorganic lead compounds. Sci Total Environ 145(1-2):55-70, https://doi.org/10.1016/0048-9697(94)90297-6. Sun CC, Wong TT, Hwang YH, Chao KY, Jee SH, Wang JD [2002]. Percutaneous absorption of inorganic lead compounds. Am Ind Hyg Assoc J 63(5):641-646, https://doi.org/10.1080/15428110208984751. 
Tak S, Davis RR, Calvert GM [2009]. Exposure to hazardous workplace noise and use of hearing protection devices among U.S. workers-NHANES, 1999-2004. Am J Ind Med 52(5):358-371, http://doi.org/10.1002/ajim.20690.

\section{Other}

CFR [2021]. Code of Federal Regulations. Washington, DC: U.S. Government Printing Office, Office of the Federal Register. 


\section{Delivering on the Nation's promise: Promoting productive workplaces through safety and health research}

Get More Information

Find NIOSH products and get answers to workplace safety and health questions:

1-800-CDC-INFO (1-800-232-4636) | TTY: 1-888-232-6348

CDC/NIOSH INFO: cdc.gov/info | cdc.gov/niosh

Monthly NIOSH eNews: cdc.gov/niosh/eNews 